\title{
EL MÉTODO CARTOGRÁFICO DE TOMÁS LÓPEZ. EL INTERROGATORIO Y LOS MAPAS DE ESPAÑA
}

\author{
POR \\ ANTONIO LÓPEZ GÓMEZ
}

\section{Introducción}

Los intentos de una cartografía moderna de España iniciados por Felipe II no hallaron continuación, el gran Atlas de El Escorial, supuesto de Esquivel, permaneció allí inédito en sus láminas de preparación y el magnífico mapa de Aragón de Labaña, fue un hito aislado. En cambio, en el xviII, con el Reformismo Ilustrado, ya se plantea de forma perentoria la necesidad de mapas detallados para el conocimiento del país, la administración, las grandes obras públicas, sobre todo caminos y canales, etc.; llega a ser una obsesión de los gobernantes y no sólo de Ensenada, aunque éste sea el más destacado en tal empeño, con el gran proyecto de Jorge Juan no realizado $(7 ; 9 ; 17)^{1}$

Estudiada por diversos autores nuestra cartografia del siglo XVIII y la significación relevante de Tomás López, así como su peculiar forma de «trabajo de gabinete» (véase Bibliografía final), no pretendemos aquí volver sobre esos temas sino considerar un aspecto esencial de su obra que, si bien ha sido analizada con detalle, en nuestra opi-

1 Las notas entre paréntesis se refieren a la Bibliografía final.

Antonio López Gómez, Instituto de Economía y Geografía, CSIC, Departamento de Geografía Universidad Autónoma, Madrid.

Estudios Geográficos

Tomo LVII, n. 225, octubre-diciembre 1996 
nión ofrece todavía algún problema sin dilucidar por completo ${ }^{2}$. Nos referimos aquí al proceso seguido para trazar los mapas de las provincias, el llamado "Atlas de España», por recopilación y síntesis de otros y también utilizando los datos obtenidos mediante cuestionarios, con las respuestas escritas y los croquis recibidos, así como los elaborados por él mismo siguiendo aquéllos o directamente según los textos. Estudiaremos así los aspectos generales necesarios y la relación con las contestaciones y dibujos que forman el llamado «Diccionario Geográfico», mediante el examen de varias provincias modernas concretas, las valencianas, las extremeñas, la de Albacete y Asturias.

Figura extraordinaria en su época, Tomás López de Vargas y Machuca (1731-1802) ${ }^{3}$ fue ya objeto de noticias por Antillón y Fernández de Navarrete, más tarde otros autores, destacando el conocido y larguísimo artículo, con catálogo de obras, del hispanista Marcel en 1907, en seguida traducido al español y básico para los análisis posteriores; aparte de varios de éstos, ha de señalarse también la publicación, sumamente útil, de las respuestas de algunas regiones y del interesantísimo catálogo de su biblioteca (véase Bibliografía final). Por ello las alusiones aquí a su vida y trabajos serán únicamente las imprescindibles para nuestro objeto. Solamente haremos especial mención de las «relaciones» o respuestas al «Interrogatorio» con sus croquis anejos (de los comunicantes o del propio López), ingente acopio de materiales manuscritos que componen el llamado «Diccionario Geográfico», considerado básico para sus mapas, aparte de su gran valor descriptivo y por ello utilizado por diversos autores, como Domínguez Ortiz (11), Cabo (6) y otros e inédito en la mayoría de los casos. Su publicación fue iniciada con las contestaciones del Reino de Valencia por Castañeda en 1919-24 (10), luego se interrumpió largo tiempo y en nuestros días han aparecido, que nosotros sepamos, las

2 Estudiar la obra de Tomás López era un proyecto muy querido de D. Manuel de Terán en sus años postreros y nos instaba a colaborar, incluso nos facilitó fotocopias de artículos. Después hemos dudado largo tiempo ante la gran diferencia entre lo que hubiera escrito el maestro y lo que pueda hacer el discípulo, pero al fin, con éste y otros trabajos que seguirán, intentamos cumplir, en su memoria, uno de sus últimos deseos, aunque sólo sea en pequeña parte.

3 El marqués de Sieteiglesias sitúa el nacimiento en 1730 , sin justificarlo, también F. Patier según la partida de defunción el 19 de julio de 1802, a «la edad de setenta y dos años» (31, p. 11 y facs. pp. 232-33). 
correspondientes a las modernas provincias de Albacete, Extremadura, Asturias, Sevilla y Almería, hay en esto cierto paralelismo con la edición de las «Relaciones Topográficas de Felipe II».

Recordaremos brevemente que López recibió estudios por el marqués de Villarias y, antes de su marcha a París en 1752, había cursado matemáticas en el Colegio Imperial madrileño con el P. Werling ${ }^{4}$, como dice él mismo, también gramática y retórica, asimismo aprendido dibujo en la Academia de Bellas Artes de San Fernando y trabajado con Jorge Juan y Antonio de Ulloa en un levantamiento topográfico cerca de El Pardo; es decir, tenía un buen bagaje previo de conocimientos. Entonces tiene importancia fundamental la conocida «Exposición» de Ensenada a Fernado VI sobre las necesidades de una buena cartografía de España, entre ellas la de grabadores; así, por proposición de Jorge Juan y Antonio de Ulloa se envía a París para perfeccionar las técnicas de mapas a Tomás López y Juan de la Cruz Cano, también destacado cartógrafo después; para otros tipos de grabado a Manuel Salvador Carmona y Alonso Cruzado.

Se sabe poco de su larga estancia parisina, durante nueve años, seguramente en casa del grabador y mercader de estampas Guillaume, contrayendo matrimonio con su hija (31, p. 14); siguió tres cursos de matemáticas en el colegio Mazarino, asistió a las clases del abate La Caille, muy ligado a Cassini en la medición del meridiano de París; él mismo dice que asistió puntualmente a las clases de geografía en el citado colegio, a las de astronomía de La Lande, a las de Le Monnier y otros y al estudio de D’Anville, desempeñando sus obligaciones a satisfacción del embajador español; quizás fue también alumno de Guillermo Delahaye, grabador de D'Anville (28, pp. 143 44). La relación con éste último fue decisiva tanto para López como para Cruz Cano, como ya señaló Marcel y han subrayado después otros autores; debió adquirir una profunda formación en el conocimiento, uso y recopilación de mapas, así como en la confección, incluyendo dibujo y grabado. Sin embargo, siguiendo a su maestro, no realizaba levantamientos. Se hizo así un completo cartógrafo de gabinete, como ya muestran los primeros trabajos, una media docena, realizados aun en París, unos con Cruz Cano, otros solo, la mayoría

${ }_{4}$ Debe ser el jesuita checo Juan Wendlingen, profesor entonces en dicho centro, autor de unos Elementos de Matemáticas y también se le atribuyen varios opósculos sobre eclipses observados en Madrid (9, p. 121). 
publicados por Antonio Sanz en Madrid, como detalla Marcel, quien señala que no tienen personalidad y son, sin duda, para ganar algún dinero (28, pp. 144-47).

Vuelto a España en 1760 y por disposición del marqués de Esquilache se le conceden cien doblones, con agregación a la Secretaría de Estado, ínterin se fundaba la Academia de las Ciencias, como premio a sus trabajos públicos y particulares en esa secretaría (31, p. 12). Ignoramos cuales fueran pero el hecho fundamental es que inicia una intensísima labor de publicación, en la cual destacan sobre todo los mapas de las provincias y reinos de entonces y de los territorios de las órdenes militares. Recibió el título de «Geógrafo de los Dominios de Su Majestad» (1772) y fue miembro de diversas sociedades y academias, entre ellas la de la Historia, el primer geógrafo de ésta. Aspecto básico de su trabajo fue el desarrollo de un proceso integral de confección, grabado y venta, en un establecimiento completo, publicando sueltos los mapas que compondrían un futuro atlas de España, imprescindible entonces y gran novedad, en realidad por entregas, pero sin periodicidad fija, iniciando así un nuevo sistema; bastantes de sus compradores los encuadernaron luego para formar atlas facticios, de contenido variable y de los cuales hay varios ejemplares, por ejemplo, en la Biblioteca Nacional, Academia de la Historia, Instituto de Geografía del CSIC, Servicio Geográfico del Ejército, etc., ya que el Atlas completo de España sólo lo publicaron después sus hijos en 1810. Ha de añadirse que, además del éxito científico, también alcanzó el económico, como muestran la considerable herencia que deja (31) y sus sucesivos domicilios, primero uno modesto en el barrio popular de Lavapiés, luego otros mucho mejores, próximos a la Puerta del Sol, en las céntricas e importantes calles de Carretas y Atocha, como exponemos en otro lugar (25).

\section{Las fuentes de los mapas de España}

Como es sabido López alude muchas veces en la cartela de sus mapas a las fuentes utilizadas (9, pp. 171-73), en unos casos de forma vaga y general, en otros citando los impresos o manuscritos que le sirven de base; en algunas ocasiones se refiere de manera imprecisa a «memorias de naturales», deben ser encuestas $u$ otras peticio-

$$
-670-
$$


nes, pero a veces llega a indicar nominalmente las personas y localidades, en larguísima lista, como la de los corregidores y sobre todo curas en el Reino de Valencia (2. ${ }^{a}$ edición) y otros diversos de la década de 1780. No podemos analizar aquí la calidad de esas fuentes, pero se plantea inmediatamente la pregunta de dónde las manejó.

En el catálogo de su biblioteca, que figura en la testamentaría (publicación de F. Patier), no se mencionan expresamente los voluminosos legajos que corresponderían a las contestaciones del «Interrogatorio», el después llamado «Diccionario Geográfico», pero puede ser la parte esencial del indeterminado núm. 360 (31, pp. 33 y 137), «Manuscritos y estampas», con una de las valoraciones más altas, 1.200 reales (de un total de 31.285 reales y 599 títulos); no se detalla contenido, lo cual es muy de lamentar ya que, con mucha probabilidad, además de las contestaciones, podrían ser también mapas, de los numerosos que cita como utilizados para los suyos, pero nada se puede precisar. En cambio apenas tendría interés el núm. 580, «Varios papeles en dos legajos», valorados en sólo 12 reales (31, p. 189).

En su excelente biblioteca, además de esos legajos fundamentales, había valiosas obras y atlas generales, incluidos tres ejemplares de Ortelius, pero la mayoría sin utilidad o muy escasa para los mapas provinciales ${ }^{5}$, en cambio destaca la magnífica carta manuscrita e incompleta de Martínez y de la Vega, hacia 1740, citada por varios autores; debido a la especial circunstancia de poseer López una copia, como ya se puede asegurar sin ninguna duda (31, pp. 41 y 139) ${ }^{6}$, y su posible carácter de antecedente, indicaremos algunos detalles. Ya afirmó Antillón (1, I, p. 27), como recogen otros autores despues, que se hicieron «operaciones geométricas para acertar a construir una carta estricta y circunstanciada de España. Con arreglo a esa operaciones, y bajo los auspicios del señor marqués de la Ensenada, trazan la deseada carta los Padres Jesuitas Martínez y de La Vega desde 1739 hasta 1743 y existe perfectamente dibujada... en la biblioteca del señor Duque del Infantado, de donde la copió un amigo mío, en cuyo poder la he visto», doliéndose de que permanezca en el olvido. Interesó mucho a Marcel, quien cree que tal amigo era López

5 Figuran también las obras de Tofiño: Derrotero de las costas de España (1787-89) y Atlas maritimo de España (1789), pero su fecha es ya muy tardía (31, p. 182-83).

6 Citado en el catálogo de la biblioteca, núm. 367, con el alto valor de 500 reales (31, p. 139 y facs. p. 140-41). 
y utilizó éste mapa para el que acompaña a su Descripción de Madrid (1763), hecho según éste sobre uno grande de hacia 1740 (28, pp. 156 y 149); se refiere extensamente a el, los autores y vicisitudes, con los fallidos intentos de adquisición por la Real Academia de la Historia en 1881 y la Real Sociedad Geográfica en 1904, ofrecido por un descendiente de los López (28, pp. 149-56; 31, pp. 33-45). Calificado a veces de «misterioso» o «fantasma» por su origen y apariciones o desapariciones, no sabemos si fue entonces o más tarde, pero quedó al fin en posesión de dicha Sociedad -probablemente su más destacada joya- y así consta en el gran catálogo de su biblioteca realizado por Gavira en 1948 (18, II, p. 97), lo analiza Vázquez Maure en 1982 (36) y como toda la citada biblioteca se halla ahora en depósito en la Biblioteca Nacional, incluyéndose en su reciente catálogo cartográfico (20, I, p. 48). Otro ejemplar (¿el original?) lo poseía Bauzá en 1807 como indica él mismo (31, pp. 42-433).

El mapa está incompleto, falta todo el cuadrante NW de la Península (Galicia, Asturias, León y Castilla la Vieja, salvo Logroño y Avila) y las Islas; la calidad es excelente y notable la escala de 1: 445.800, sus 36 recuadros forman un conjunto (entelado) pero puede considerarse, posiblemente, como un antecedente de la obra de López. No sabemos de que fecha es la copia de éste y si le sirvió de inspiración, pero resulta extraño que no la cite como fuente en sus mapas, salvo la posible alusión señalada por Marcel; sería rara una ocultación deliberada y puede ser una posesión tardía o bien no tenía autorización para su uso, pero entonces ¿cómo obtuvo la copia según indica Antillón?, ¿por sus contactos oficiales? Es un curioso enigma sin solución por ahora ${ }^{7}$.

También pudo disponer de las instalaciones y fondos de la Real Academia de San Fernando, a la cual perteneció como académico de mérito desde 1764, pero ya en 1760 le concedió, como a su compañero de pensionado Cruz Cano, «para que se puedan mantener...seis Rs. de Vn. al año», sin otro estipendio, por los grabados que se les encargase, según documento reproducido en facsímil por F.Patier (31, entre pp. 182-83); llama vivamente la atención la cantidad tan exigua, debe ser error del escribiente aunque el oficio es original rubricado. También se les permitía el uso de los instrumentos, libros y mapas

7 Según Núñez de las Cuevas, en el Mapa de los Reynos de España y Portugal de su hijo Juan López, indica tener en cuenta las operaciones geométricas de Martínez de la Vega (29 bis, p. 77). 
de la Academia, «correspondientes al estudio y exercicio de estos Profesores». No hemos podido acometer aun el examen de los fondos cartográficos de esa Academia, sin embargo parece que no hay importantes del XVIII, aunque sí bastantes del XIX.

En la de la Historia es López correspondiente en 1776, supernumerario en 1779, numerario en 1787 y tesorero desde noviembre de 1799 a noviembre de 1800 , entonces el cargo solía ser breve. En su expediente hay pocas noticias, salvo una sucinta relación de estudios y méritos, los nombramientos y la indicación sobre la necesidad de examen previo de sus obras para expresar la conformidad de la Academia. Esta, a poco de su fundación, viendo las inexactitudes y a la vez la necesidad de mapas, proyectó hacerlos pero hubo de desistir ante las dificultades (9, p. 147). Entre sus fondos, aparte de la Descripción manuscrita del Tajo de López, enumerativa y de poco valor como ya indicó Marcel, son interesantes cuatro atlas facticios de gran formato, que estamos estudiando, con encuadernación de la época, portadas e índices cuidadosamente caligrafiados, en cuya confección bien pudo intervenir López. Dos son de sus mapas, uno general de España bastante completo, similar a los de otras bibliotecas madrileñas ya mencionados, pero con el interés añadido de correcciones manuscritas quizás del propio autor; otro, mucho menos conocido, es de los territorios de las órdenes militares; asimismo hay numerosos ejemplares de mapas sueltos que llevaría a la Academia y de ellos hay referencias en las actas. Otro atlas facticio, con obras de diversos autores, corresponde a América y también hay numerosos mapas manuscritos sueltos con catalogación reciente (27). Sin embargo, para nuestro trabajo concreto, es otro atlas facticio el que tiene máximo interés.

Lleva por título, manuscrito y sin fecha, Atlas y planos de varios autores contenidos en este II tomo, numeración que debe aludir al otro de España del propio López y su origen exacto se desconoce, aunque quizás cuidara él de la recopilación. Contiene mapas, la mayoría impresos pero varios manuscritos, valiosos en sí mismos, especialmente algunos y de notoria importancia en nuestro caso, ya que no se citan en la biblioteca particular de López (31) y pudo manejar éstos para confeccionar los suyos, en tal caso el material de la Academia adquiere una relevancia especial en su obra; también podrían ser de su propiedad y luego cedidos y encuadernados antes de su muerte; posiblemente arroje luz el examen de las actas que estamos verificando. 
Sin analizar ahora con detalle dicho atlas, que reservamos para otra ocasión, en cualquier caso parece harto significativo que allí figuren diversos mapas citados como fuentes en los suyos, basten unos ejemplos referentes a los espacios aquí estudiados: en Valencia, para la $1 .^{\mathrm{a}}$ edición de 1762, el de Cassaus de 1693 (lám. XXVIII); para la 2. ${ }^{a}$ de 1788, el de este arzobispado, grabado por Hipólito Ricarte en 1761 (lám. XXIV, 2 ejs.) y el de la diócesis de Segorbe, por encargo del obispo Cano, de 1773 (lám. XXVI); en Murcia, el de Felipe Vidal y Pinilla de 1724 (autor y fecha poco visibles en extremo inferior derecho) (lám. XV).

También pudo consultar la documentación recogida para el Diccionario Geográfico proyectado por la Academia y del que sólo se imprimieron los volúmenes de Navarra y Vascongadas; para éste, asimismo, se hizo copia de las «Relaciones Topográficas de Felipe II», trasladadas allí temporalmente desde El Escorial, las cuales pudieron ser estudiadas por López, incluso servirle de guía para su propia encuesta, como supone Marcel (28, p. 164).

Finalmente, como antiguo pensionado y desde 1772 «Geógrafo de los Dominios de Su Majestad» tendría acceso a los fondos cartográficos oficiales, como subrayó Marcel (28, p. 156). Ya a finales de siglo el interés por la compilación de mapas llevó a la creación de un gabinete en la Secretaría de Estado (34, pp. 107-108), a él se remitió la gran colección reunida en París por Megallón. Es el resultado de una comisión de Godoy en 1795 a los López para que acopiasen mapas. Según Real orden de 1796 se encarga a los representantes españoles en el extranjero que formen colecciones de mapas y las remitan; además se comisionó a varias personas para que hicieran investigaciones en tal sentido en los principales países europeos. Como resultado, por el capitán de navío José Mendoza Rius, miembro de la Real Sociedad de Londres, se hicieron dos catálogos, uno de libros de Geografía y viajes y otro de mapas, cartas marinas, itinerarios, derrotas, etc., publicados en Gran Bretaña. El gabinete estuvo dirigido por Tomás López, Manuel Abella, José Narciso de Aparici y Sebastián de Miñano. Luego, en tiempos de Fernando VII, queda abandonado y se pierden muchas obras. Bastante después, en 1844 el ministro Mon ordena la catalogación y más tarde pasaron los restos a la Biblioteca Nacional. La mayoría de los grandes fondos históricos del actual Servicio Geográfico del Ejército proceden del antiguo Depósito de la Guerra, incluso mapas manuscritos de López, como ya señaló Marcel. 


\section{El método: opiniones diversas}

El metodo utilizado por Tomás López ha sido objeto de afirmaciones variadas, sobre todo respecto a las contestaciones del llamado «Diccionario Geográfico», desde estimarlas básicas hasta sólo complementarias, en general sin muchas precisiones y sin examen directo; asimismo se ha indicado que la finalidad de aquéllas era también, o fundamentalmente, un Diccionario en sentido estricto.

Es bien indicativo que quien ordenase la encuadernación de tales documentos, al finalizar el siglo XIX o comienzos del nuestro, ya puso como título genérico el de «Diccionario Geográfico» (que perdura), pensando sin duda en lo que parece su contenido básico.

En su estudio sobre la cartografía en España, en 1904, Prudent se refiere al Atlas de López, «publicado de 1765 a 1798», señalando la diversidad de escalas y el contenido detallado de un ejemplar de la edición de 1810. Aunque sin mención concreta del interrogatorio, parece concederle gran importancia al decir que para los mapas «se apoya más en las noticias descriptivas proporcionadas por el alto y bajo clero, por los corregidores, intendentes, ingenieros jefes, y sobre algunos mapas manuscritos locales y un pequeño número de levantamientos regulares» (32, p. 401).

En su fundamental trabajo, que utilizamos extensamente, Marcel es muy preciso sobre la cuestión que nos ocupa aquí: la finalidad de las encuestas, resultados y utilización. Examinó los originales en la Biblioteca Nacional, como se deduce de algunas citas, aunque no en detalle seguramente; afirma que López empezó esa labor en la década de 1760: «dándose cuenta de las dificultades que encontraba en la ejecución de sus mapas de las diversas provincias de España, tuvo la dichosa inspiración de dirigirse oficialmente... a obispos, curas y otros funcionarios para pedirles noticias relativas a su diócesis o su parroquia». Como ejemplo pone la carta del prelado de Osma, de 1768, en la cual éste se lamenta a López de no haber persona en el obispado capaz de satisfacer sus demandas. Menciona asimismo el texto que acompaña al mapa de las Sierras de Guadalupe, con siete cartas o relaciones que enviaron los curas en 1765 y 1766 (28, pp. 161-63). Podríamos añadir nosotros la relación y cartas de Bellvis de Monroy de 1765, con curioso esquema radial y amplio croquis de López, éste sin fecha (3, pp. 83-89). Anticiparemos nuestra opinión de

$$
-675-
$$


que en ésos y quizás otros casos similares se trata, más bien, de peticiones aisladas de noticias y no del interrogatorio general que sería sobre todo después de 1770 , cuando se otorga a López el título de «Geógrafo de los Dominios de Su Majestad», que utiliza en sus encuestas. En los volúmenes publicados, al menos, casi todas las contestaciones son posteriores. El caso de Guadalupe plantea, además, el problema de que el mapa es de 1781 y la amplia relación del lugar, incluida entre las de Extremadura y con referencia expresa al interrogatorio, es de 1787 (3, pp. 226-30), como detallaremos después.

También se refiere Marcel, en nota (28, p. 161), a que hay «una centena de mapas, en su mayoría de un dibujo infantil, pero que eran, sin embargo, preciosos para López en el sentido de que le suministraban un gran número de nombres de localidades con su situación respectiva evaluable en leguas», aunque el valor de éstas era un problema. Aparte del número, que es mucho mayor, llama la atención, que no distinga entre los dibujos remitidos y los fundamentales croquis de López, tan peculiares y fáciles de reconocer, más numerosos y realizados sobre aquéllos o interpretando los textos directamente.

Indica después la falta de crítica, al menos expresa, de tales fuentes, necesaria dado su origen: «no tenemos ninguna prueba que esas relaciones hayan sido examinadas por López con un espíritu crítico. No están acompañadas de ninguna reflexión, de ninguna apreciación», especialmente sobre hechos extraordinarios en exaltación de la patria chica, a diferencia de su maestro D'Anville que «comprobaba y confrontaba las informaciones de sus correspondientes» (28, p. 161). Es éste un tema general en el que insistirán después otros autores y al que ya se había referido Antillón en otro aspecto, concretamente la errónea fijación de coordenadas en los mapas, con ejemplos diversos, aunque reconoce el indiscutible mérito general de López (2, pp. XV-XVI). Correspondería a otro trabajo examinar la calidad de los mapas, con sus errores y aciertos, en el contexto de la época; sólo apuntaremos, por nuestra parte que, aun sin mención expresa, la realidad es que sí hay correcciones de algunos datos, especialmente la situación; ésta se halla indicada en las respuestas, en general, únicamente por los cuatro rumbos fundamentales, pero en sus croquis también según los intermedios, como hemos comprobado en muchos casos. Cuestión distinta, que nos llevaría lejos, es el origen de esas correcciones, necesariamente otras noticias o un mapa anterior, im- 
preso o manuscrito, de otro autor o del propio López; pero si en esa fuente había inexactitudes, pasarían también al nuevo mapa. En cuanto a los definitivos, como veremos después con el ejemplo de las dos ediciones de Valencia, en ambas, al indicar los mapas utilizados se refiere a su calidad, el mejor el de Cassaus de 1693, e incluso a las correcciones sobre ellos mediante otros, por ejemplo uno manuscrito sobre las costas; asimismo se refiere a las coordenadas de la capital, según autores diversos y las que él estima más exactas, bien es verdad que sin aducir motivos concretos.

Lo importante, en nuestro caso, es el reconocimiento expreso por Marcel de la gran utilidad para López del interrogatorio y sus dibujos en el trazado de sus mapas posteriores a los primeros como recogimos al comienzo. Pero tampoco hay duda en su opinión sobre la otra finalidad, un diccionario.

Así añade a continuación: «López se ha contentado con acumular estos documentos con la idea de publicar un Diccionario geográfico de España que habría sido acompañado de mapas de provincias, obispados, partidos, corregimientos y planos de ciudades». Dice después que en los treinta años transcurridos, entre las primeras y últimas noticias recibidas, hay poca unidad y contemporaneidad «en el diccionario soñado por nuestro geógrafo ¿Es ésta la razón que le hizo dudar en utilizar esos materiales? no lo pensamos, puesto que hasta el final de su vida solicita nuevos». Finalmente se felicita Marcel de la conservación, como utilísimos materiales para estudiar la época, aunque "no pueden ni han podido servir a un diccionario» (28, pp. 164-65). Finalmente se refiere a la semejanza del cuestionario con las Relaciones Topográficas de Felipe II y al Diccionario iniciado por la Academia de la Historia, aunque estima que López no se inspiró en este último (28, p. 167). Demasiado prolija ha resultado la mención de Marcel, pero la hemos creido necesaria como antecedente fundamental y muchas veces repetido.

Castañeda, en 1919, al iniciar la publicación de las relaciones del Reino de Valencia, según un manuscrito propio, en la introducción (10, pp. 4-5) menciona intentos anteriores como la Descripción y Cosmografía de España de Hernando Colón, el Nomenclátor de 1550 y las Relaciones de Felipe II. Después, en las de López, dice: «hallé compendiados en los citados manuscritos y gráficamente expuesta la historia y la geografía de multitud de pueblos del antiguo Reino de 
Valencia... con todo detenimiento y verdad y traducidos luego de modo incomparable en magníficos mapas, dibujados por la experta mano del geógrafo don Tomás López Enguídanos» (sic); luego incluye el interrogatorio. No estudia la figura de López por ser «personalidad conocida y documentada», aunque no cita a Marcel y llama vivamente la atención que no aluda siquiera a los volúmenes del resto de España en la Biblioteca Nacional. Ha de subrayarse que incluye mapas del cuestionario y croquis del propio López distinguiéndolos, aunque a veces con alguna atribución incorrecta (24). En cuanto al error en el segundo apellido, que López añade pocas veces en sus mapas, se explica por confusión con otro grabador de la época, el que hizo láminas de Cavanilles, por ejemplo las de la Historia Natural y Geografía del Reino de Valencia, familiar a Castañeda.

Reparaz estudia el método de López como cartógrafo de despacho y reconoce, siguiendo a Marcel, que de esa forma trabajaban Delisle y D’Anville, pero éstos con gran espíritu crítico, como también después Antillón. No se refiere al empleo de otros mapas anteriores, lo dará como implícito, textualmente afirma que López «se basa en multitud de informaciones que procura obtener de todas las regiones de España. Dirígese principalmente al clero». El conjunto son los miles de documentos de la Biblioteca Nacional, el llamado Diccionario Geográfico, además de otros aparte que señala (34, p. 112); reproduce la carta-circular que enviaba López, salvo la nota sobre petición de croquis (que es, sin embargo, fundamental). Añade que «no sólo no hace la menor medida ni toma el menor ángulo sobre el terreno, sino que ni siquiera lo conoce de vista, teniendo siempre que fundamentarse en las respuestas que le dan personas de muy diverso nivel cultural». No hay duda, pues, de que Reparaz considera básicas las respuestas, aunque al citar de pasada «fuentes que indica al margen de sus mapas» (34, pp. 113-14) es evidente que vería las menciones de otros mapas al recoger varios autores en el de Soria. El método da lugar a errores notorios y así pone los ejemplos de las coordenadas de Burgos y Soria en los mapas respectivos, que indica López según «una comparación prudente», sin crítica alguna, también se refiere a la desembocadura del Besaya. Sin embargo, siguiendo a Marcel, reconoce el mérito indiscutible de López y su influencia durante largo tiempo.

Esencial en la obra de López, aunque a menudo no se subraya, según Vázquez Maure, es el gran nivel que alcanza en el grabado (in- 
cluida la rotulación) e impresión, muy superiores a lo precedente (37, p. 72); en cambio el contenido es más discutible, con errores de veintenas de kilómetros. Considera esencial en su método los millares de contestaciones («activididad epistolar increible»), ya que su trabajo «asombroso es transformar estas cartas en dibujos sobre el mapa... sin duda manejaba también toda clase de mapas existentes y sospecho que el Martínez y de la Vega debió de serle de gran utilidad».

En su extenso análisis de López, especialmente sobre los mapas, Capel (9, pp. 152-83) lo considera ejemplo perfecto de geógrafo de gabinete que trabaja con fuentes de segunda mano, por tanto siempre preocupado por las medidas itinerarias y su conversión, a ello dedica gran parte del tomo II de sus Principios geográficos aplicados al uso de los mapas y su mismo discurso de ingreso en la Academia de la Historia sobre las medidas de los hebreos. Base de su trabajo son los mapas impresos o manuscritos que recopila, detallando los ejemplos de varias provincias, pero como eran a veces insuficientes decide enviar el interrogatorio (lo incluye) y tales «contestaciones con los planos que solicitaba, constituyen hoy una valiosa fuente para la historia del siglo XVIII, inexplicablemente poco utilizadas», pero su espaciamiento temporal, el gran número y quizás el espíritu escasamente crítico «las harían seguramente menos útiles de lo que podía esperarse del esfuerzo desplegado en obtenerlas». Sin embargo, insistió en su petición «quizás con la idea de publicar un Diccionario Geográfico de España», proyecto que también tenía la Academia de la Historia de la que formaba parte (9, pp. 170-71). Por consiguiente admite doble fin aunque posible escasa utilidad. Asimismo señala la edición de Valencia por Castañeda (única entonces) «incluyendo los croquis realizados por los corresponsales y las adaptaciones de López», siendo uno de los pocos que mencionan éstas últimas (9, p. 173, nota). También cita la obra de Vayssière sobre análisis semiótico de los bocetos manuscritos de los corresponsales, tema tan discutible y en el que no podemos entrar.

Para concluir este apartado nos referimos a algunos trabajos últimos. Carmen Liter, en 1991 (19), supone en las relaciones doble finalidad: completar los mapas y realizar un diccionario. Señala así que López utiliza fuentes cartográficas de la época y anteriores, «numerosos levantamientos hechos en España en el siglo XvIII por marinos, ingenieros militares, agrimensores, etc. Para completar y poner a punto de un modo exhaustivo todos esos materiales decide solicitar 
información de todas las regiones» y por estar realizando un mapa de España pide el croquis del pueblo y su contorno. Se refiere después al interrogatoirio, que reproduce, para finalizar señalando que «realizó un enorme trabajo reuniendo e intentando unificar y sintetizar todos esos materiales. Y paralelamente iba archivando estas contestaciones con la idea de publicar un Diccionario geográfico de España», que también intentaba la Academia de la Historia (19, pp. 24-26).

En la utilísima publicación de las relaciones de la moderna provincia de Albacete, con extensa introducción, Rodríguez de la Torre y Cano Valero también explicitan claramente las dos finalidades, posiblemente sucesivas, cartográfica y enciclopédica. Se refieren ampliamente al plan y su gran interés, estimando que el valor descriptivo supera mucho al cartográfico. Afirman que constituye «una abundantísima documentación... que en su idea primigenia son sólo una base de datos para la confección de mapas, abocan, quizás inadvertidamente, a la formación de un Diccionario geográfico» (35, p. 39). Después de examinar con detalle el valor geográfico, repiten, en conclusión (p. 88): «solemos olvidarnos que la finalidad primigenia de la obra era la de cartografiar mapas de las diócesis españolas... parece evidente para muchos que los «medios» (millares y millares de documentos) desbordan a los» fines» (diseño cartográfico de mapas diocesanos), de tal forma que se ha creido ver en la finalidad de la ingente obra, no un atlas con datos, sino una magna enciclopedia atlas». A la parte gráfica de las relaciones se refieren brevemente (35, pp. 88-89), ya que en las localidades hoy albacetenses es pobre en general y no hay ningún croquis del propio López; incluso tres de los enviados por los corresponsales los consideran tan malos que no los reproducen.

Igualmente útil es la publicación de Extremadura, con bastantes reproducciones de croquis pero no todos, Barrientos (3, pp. 11-12) destaca el valor geográfico y se refiere al intento de Diccionario de la Academia de la Historia, aunque también menciona la importancia de la labor cartográfica de López; señala igualmente que «uno de los objetivos primordiales... era la elaboración pictográfica de mapas», reclamando para ello la orientación, distancias y localización de los pueblos. Es decir posible finalidad doble. En cambio Rodríguez Cancho, en la misma obra, analizando los tres grandes trabajos de información de la época: el Catastro de Ensenada, las averiguaciones de la Real Audiencia en Extremadura y el interrogatorio de López, con- 
sidera como finalidad de éste la de un Diccionario geográfico (3, pp. 16-17), sin aludir a la utilidad cartográfica.

En la edición de Asturias, Merinero y Barrientos dan primacía indicutible al primer aspecto y así comienza la introducción: «El llamado frecuentemente «Diccionario Geográfico de Tomás López» no es sino un proyecto inacabado para proporcionar a la corona ilustrada española un Diccionario competitivo con las ediciones elaboradas desde otros Estados europeos. Proyecto inacabado en la medida en que no existe la obra final» y más adelante: «Sin lugar a dudas debe situarse su trabajo en la línea de los objetivos de la Real Academia de la Historia» no logrados y López «no haría sino añadir su propio fracaso al de la Academia». Después sólo aluden brevemente a que adquirió nombradía mediante sus mapas, de larga vigencia, y a su formación en París (29, pp. 11-12).

Por último, en una referencia a López y sus dos mapas de Valencia, señala Faus la temprana realización, en 1762, del primero, que debía formar parte del ambicioso Atlas de España. Años más tarde emprende la recogida sistemática de datos geográficos mediante el cuestionario y «se va a servir de las contestaciones para formar, entre otros» el de 1788. Como geógrafo de gabinete utiliza los mapas de otros autores, que indica (también figuran en la $1 .^{a}$ edición) «y los escritos remitidos por una larga lista de colaboradores» (12, pp. 23 y 25). No se refiere al supuesto Diccionario como tal, en cambio alude claramente a la realización de mapas antes y después del interrogatorio, como ya apuntó Marcel.

\section{Las fuentes cartográficas}

No entramos aquí en el examen detallado del método general y de todas las fuentes, lo que sería muy largo y complejo, especialmente los mapas de otros autores, impresos unos, otros manuscritos y en paradero hoy desconocido; nos ceñimos esencialmente a las relaciones y croquis del llamado «Diccionario Geográfico», sin embargo parece oportuno incluir algunas consideraciones previas sobre las fuentes cartográficas.

El hábil empleo de mapas de otros autores y noticias recibidas, o método de gabinete, es, en definitiva, base de su trabajo, el del «géografo cuia profesion exerce dentro de su estudio», sin medir tierras 
ni hallar coordenadas, como él mismo indica en la 2. ${ }^{a}$ edición del mapa de Valencia de 1788, añadiendo que es la única forma posible para una labor personal de carácter genérico. A esas dos cuestiones se refiere varias veces.

La fijación de las coordenadas para ajustar sus mapas le preocupa mucho, como es lógico, ya que sabe de sobra la imprecisión de entonces, especialmente en la longitud, aunque reconoce su impotencia y afirma, en el citado mapa de Valencia, que ha de ser obra de astrónomos y sólo conoce la de Madrid obtenida por Jorge Juan. Así, en sus mapas, expone los datos de varios autores y se decanta por uno sin crítica expresa, difícil por otra parte en el recuadro de un mapa. Veamos unos ejemplos.

En el mapa de Soria (1783) dice haber examinado las coordenadas (de la ciudad) según «D’Anville, De Lisle, Medrano, Serrano, Rocamora, Chaves, Machado y otros», sin justificación precisa opta por $41^{\circ} 50^{\prime} \mathrm{N}$ y $14^{\circ} 15^{\prime} \mathrm{E}$ del pico de Teide o de Tenerife; sin embargo advierte: "como todas las que puedan hacerse de esa misma forma, valdrá sólo hasta que de intento se efectúen observaciones sobre la propia ciudad y otras del reino con los instrumentos correspondientes».

En la 1. ${ }^{a}$ edición de Valencia (1762) reproduce las de varios autores: Nolin, Incelin, Cassaus, Harris en el Diccionario de La Martinière (libro que consta en su biblioteca), Serrano según las «Tablas Philípicas» y la diferencia de longitud con Madrid según Tosca, señalando al fin la que él adopta, sin más explicación. En la extensa nota de la $2 .^{a}$ edición (1788) escribe que «Estas observaciones no las puede executar ningún particular a su costa» por los gastos y gentes necesarias, además han de ser por persona dedicada «a la Astronomía sola sin tener que atender otros ramos diferentes»; así espera que algún día haya en España quien «subministre a los geógrafos latitudes y longitudes de los pueblos», recordando que en París se halla Salvador Ximénez Coronado dedicado a esa profesión por encargo del gobierno.

La cuestión de las coordenadas erróneas en los mapas de Tomás López fue pronto criticada duramente por Antillón, quien se preocupa mucho de ello para el pequeño, pero excelente mapa de sus Elementos de Geografía (1808), dedicando varias páginas al tema. Afirma de López «su casi inconcebible desconcierto en todas las situaciones astronómicas de los pueblos; y no solamente en la longitud, sino en la latitud misma. Pudo sin culpa equivocarse el geógrafo, porque de- 
lineaba por datos agenos; pero es inescusable en las contradiciones continuas», cita los valores distintos de Molina y Cuenca en el mapa general de 1792 y el particular de Cuenca, los de Tafalla y Sangüesa en el general y el de Navarra, Fitero en los de Navarra y Soria, «así podría hacerse una larga enumeración de exemplos... otros mayores y casi increíbles, por lo enormes, he hallado en las otras provincias de España que he recorrido». A tales casos se han referido también Reparaz y Patier (34, p. 114; 31, p. 22). A pesar de tan acerba crítica, Antillón reconoce que los mapas de López «son lo menos malo que hay... el zelo y laboriosidad de su autor merecen respeto y gratitud. $\mathrm{Su}$ atlas es el único que hasta ahora tenemos de las provincias del reyno; a quien acomete empresa tan grande deben escusarsele muchos defectos y equivocaciones»; sólo el gobierno puede acometer el levantamiento de un mapa a gran escala (1, pp. XVI-XVII). Dedica después Antillón media docena de páginas al problema de las coordenadas de las costas y del interior, según observaciones de diversos autores, y al final señala las de 84 lugares y otras 20 de latitudes inéditas (1, pp. XVI-XVII y 150-53); por las fechas, son de finales del XVIII y comienzos del XIX, es decir, casi todas posteriores a los mapas de López. Ha sido larga la cita pero la creemos necesaria para expresar los términos justos de la cuestión.

En lo que se refiere a los levantamientos sobre el terreno, que practicaban otros cartógrafos, no desconocía López la técnica, por lo menos en los aspectos básicos, ya que hay un testimonio de juventud de él mismo, bien preciso y el cual sólo hemos visto recogido por $\mathrm{F}$. Patier (31, p. 11). En su expediente de la Academia de la Historia, en el memorial solicitando plaza, dice que en 1752 -antes de salir hacia París- asistió con Jorge Juan y Antonio de Ulloa «seis meses continuos a la medición y levantamiento de un plano topográfico del Real Bosque de Viñuelas», junto a El Pardo, adquirido por Fernando VI. La categoría de tales maestros exime de más comentarios y no sabemos el verdadero aprendizaje de López, pero nos podemos preguntar cuál habría sido su futuro cartográfico de seguir con aquéllos y no marchar a París; sin duda muy distinto al de editor de mapas «de gabinete» como aprendiera con D'Anville.

Bien explícita de su método es, por ejemplo, la mencionada $2 .^{a}$ edición del mapa de Valencia, donde anota que un geógrafo se sirve de los materiales recibidos, ya que en toda su vida «haría pocos ma-

$$
-683-
$$


pas si fuera de su inspección medir la tierra de ellos y observar las latitudes y longitudes de los pueblos». En otro lugar, en los Principios geográficos aplicados al uso de los mapas, como recogen varios autores (9, p. 167; 19, p. 24; 31, p. 21), justifica su método; aunque el mejor «de hacer un mapa es andando y midiendo la tierra», no es posible para un particular «el geógrafo trabaja en su casa, teniendo a la vista varios papeles de un mismo terreno, no es ministerio suyo levantar planos, porque para eso hay otra clase de gentes...si los geógrafos necesitasen ver y medir las tierras que comprehenden sus mapas, ninguno hubiese podido durante toda su vida publicar uno de las cuatro partes de la tierra y es así que hacen las cuatro».

Establecido su método, revela su probidad científica precisando la mayoría de las veces los mapas que ha utilizado para trazar los suyos, en ocasiones con alguna anotación crítica; pongamos unos ejemplos. En la 1. ${ }^{a}$ edición de Valencia, como detallamos en otro lugar (25), dice haber seguido esencialmente el de 1693 de Cassaus, quien «visitó lugares, midió terrenos y consiguió hacer un mapa más completo y exacto que el que havía hecho antes $\mathrm{D}$. Pedro Texeira», añade que tuvo error en la longitud, sin especificar, y lo corrige, así como otros en la costa sur que arregla mediante un mapa manuscrito del cadete de artillería Carlos Denauy; en cambio considera pequeños e inexactos los de los franceses Nolin e Incelin.

En la 2. ${ }^{a}$ edición vuelve a citarlos y además añade: «Mapas impresos del Arzobispado», debe ser el de 1761 que incluye Castañeda en su edición. Después, en la larguísima lista de «documentos» recibidos o respuestas, menciona al principio dos mapas impresos de la diócesis de Segorbe, uno de ellos moderno, del tiempo del obispo Cano, seguramente el incluido en la relación de Altura (10, I, p. 179), sin fecha. Más adelante ( $3 .^{\mathrm{a}}$ columna) otros manuscritos que no conocemos, dos de la diócesis de Orihuela, uno antiguo y otro moderno de Fr. Luis de Petrel, capuchino profesor de Matemáticas; finalmente «un trozo de mapa desde Novelda a Cartagena» de Jorge Juan nada menos. Aparte, claro está, los más o menos toscos borradores locales enviados desde los pueblos.

En la 1. ${ }^{a}$ edición de Extremadura (1766) indica como fuentes el mapa manuscrito de Luis Josef Velázquez y el del maestre de campo 
Luis Venegas. En la 2. ${ }^{a}$ edición también las noticias de los naturales que no tiene espacio para detallar.

En el de Cuenca (1766), el del obispado de Bartolomé Ferrer y el manuscrito del señorío de Molina de Gregorio López. En el de Murcia de 1768, el impreso de Felipe Vidal y Pinilla y las memorias particulares remitidas por los naturales, sin especificar. Los ejemplos se podrían multiplicar. En las regiones fronterizas pirenaicas también recurre a franceses: en Aragón (1765), además de Labaña, el «célebre» de los Pirineos de Roussel y los de Seyra y D'Anville; en Cataluña (1776), aparte de Josef Aparici y Francisco Garma, a Darnius y Roussel (9, pp. 171-73).

Esa diversidad de fuentes también puede ser desafortunada, según apunta Marcel, al multiplicar los errores, como en el caso de Aragón en que que obtiene un resultado muy inferior al de Labaña, lo que ya subrayó Antillón, incluso alterando las coordenadas de Zaragoza cuando no había observaciones astronómicas nuevas (28, p. 186).

En otros casos es menos explícito, el de Vizcaya de 1769 está «Compuesto sobre algunos mapas, manuscritos, noticias de sus naturales y en particular las de Mr. Guillermo Bowles»; el de Asturias de 1777 con un mapa manuscrito, noticias de Campomanes y de los naturales. En otros no dirá nada: Sevilla (1767), Avila (1769), Segovia (1773), etc. En lo que se refiere a respuestas al interrogatorio, además de los mapas utilizados, en los que edita en la década de 1770 y siguiente son frecuentes largas listas de colaboradores: Zamora (1773), Palencia (1782), Salamanca (1783), León (1786) Soria (1783), Valencia (1788), etc. En resumen, la variedad es grande pero domina la mención de las fuentes.

Concluiremos con otra muestra muy distinta, la del pequeño Atlas elemental moderno de 1792. Reconoce sin ambages que «siendo uno de los más exactos en la clase de abreviados el pequeño atlas moderno» publicado en París en 1783 por el grabador Lattré «me pareció servirme de él con preferencia a otro, por ser compuesto éste por uno de los buenos geógrafos de Francia, aunque no lo declara el grabador...he formado el nuevo (mapa) de España...hice también alguna corrección en otros para su mayor exactitud.» En suma se podrán reprochar a López otras cosas, pero de ninguna manera la ocultación de sus fuentes cartográficas.

$$
-685-
$$


Las respuestas y sus dibujos. Rasgos generales

Intentamos examinar ahora tres aspectos fundamentales, estrechamente relacionados entre sí, sobre el uso de este otro material para la edición de los mapas, considerado en general como básico: 1) Las respuestas al interrogatorio y su utilización cartográfica, prescindiendo de su valor descriptivo. Adelantamos que no es posible pasar directamente del texto a un mapa provincial, se requiere el intermedio de mapas o croquis locales para su ensamble. 2) Los «mapas» remitidos con las contestaciones son, en general, muy elementales, de muy difícil empleo directo e insuficientes en número. 3) Son esenciales los croquis del propio López basados en tales «mapas» recibidos y en el texto o, a falta de ellos, mediante la interpretación directa de las respuestas, laboriosísima tarea realizada con gran pericia.

Tales cuestiones, a menudo poco precisadas, creemos que necesitan un examen minucioso para comprender el significado de ese material en el método seguido por López para sus mapas de España.

Las respuestas. Como es bien sabido, el llamado «Diccionario Geográfico» consiste, en realidad, en las respuestas a un interrogatorio impreso de 15 cuestiones que enviaba Tomás López a autoridades civiles o eclesiásticas y especialmente a curas de los pueblos; el nombre tradicional responde al título que figura en la encuadernación posterior de tales documentos. Era correspondencia particular a él dirigida y entonces se hallaría en bastantes legajos, pero llama la atención que no se explicite en el preciso catálogo de su biblioteca, aunque puede ser, como ya se apuntó, el indeterminado núm. 360, de «manuscritos y estampas», muy valorado (31, pp. 33 y 137). Carece de sentido una ocultación deliberada por sus hijos para futuros trabajos, ya que tales respuestas se indican como fuente en diversos mapas, con detallada relación de personas y localidades, como ya se expuso.

El hecho es que aparecen casi un siglo después en la gran biblioteca de Ricardo Heredia, subastada en París en 1894, como indican Rodríguez de la Torre y Cano Valero (35, p. 40); allí figura como lote 7.509 un conjunto de Tomás López descrito sin ninguna duda: alrededor de 1.600 cuadernillos manuscritos con planos y mapas, respuestas recibidas para su mapa de España. No se sabe cómo llegaron a la Biblioteca Nacional; ordenadas alfabéticamente por provincias mo- 
dernas, con algunos trastueques, se encuadernaron en 20 volúmenes, algunos dobles de provincias limítrofes. Indicados por diversos autores no los vamos a repetir y hay también sueltas en otros legajos (35, pp. 42-43). Existe un utilísimo catálogo de lugares de C.Olarán, mecanografiado, en la misma Sección de Manuscritos (30). Faltan las relaciones de Santander, Salamanca, las tres provincias de Aragón, las cuatro catalanas y los Archipiélagos, así como las valencianas, pero éstas son conocidas por otra fuente. Formaban un manuscrito aparte, sin que sepamos la razón, el cual, procedente de un amigo no nombrado, poseía Vicente Castañeda (después académico y secretario en la de Historia) y publicado por él (10), como ya se ha dicho; desafortunadamente ignoramos su paradero actual.

Recordaremos brevemente cómo era el interrogatorio y las contestaciones. Aquél ha sido publicado por Marcel y otros autores (Castañeda, Domínguez Ortiz, Capel, Rodríguez de la Torre, Líter, Barrientos, etc.) no lo vamos a repetir completo y sólo indicaremos su esquema. Junto con una carta-circular firmada, subrayando la importancia de la empresa, básicamente un mapa de la diócesis, enviaba el Interrogatorio de 15 preguntas que se pueden reunir en dos grupos de distinto sentido. Domina el cartográfico en las seis primeras: carácter jurídico del pueblo y número de vecinos, eclesiástico con sus conventos, ermitas, etc. (se refleja con signos en los mapas), distancias en leguas a lugares colindantes en los cuatro rumbos fundamentales, ríos o arroyos con sus puentes, sierras, bosques y montes. Las otras son geográfico-históricas: armas y sucesos, frutos, fábricas, ferias o mercados, enseñanza, gobierno, enfermedades, recursos mineros e inscripciones. Además, en «Nota», se pide, y esto es fundamental, «unas especies de mapas o planos de sus respectivos territorios de dos o tres leguas en contorno de su Pueblo». La doble finalidad parece clara.

En la carta-circular que envía con el interrogatorio añade al final que «Si V. lo permite daré cuenta de su nombre y circunstancias en el prólogo de la obra, como concurrente con su mediacion y trabajo, sin olvidar todos los sujetos que ayuden a V. en el encargo» (véase, por ejemplo, 35, facs. p. 31). Efectivamente, en diversos mapas, desde finales de la década de 1770, ya realizada la encuesta, además de mencionar los utilizados impresos o manuscritos, hay larga lista de nombres y lugares de los colaboradores, sobre todo párrocos, por 
ejemplo en las Sierras de Guadalupe (1781), Palencia (1782), Salamanca y Soria (1783), Toro (1784), León y Carrión (1786), etc.; también en la segunda edición de Valencia (1788), en cambio en la segunda de Extremadura (1798) se excusa de no hacerlo por falta de espacio. Claramente hay un doble fin, el de agradecimiento-estímulo para los colaboradores y el de probidad científica, con expresión de la gran labor de acopio de información «de campo».

La calidad y detalle varían muchísimo. Realizadas en su mayoría por los párrocos, las hay sumamente breves, con pocos más datos cartográficos que el nombre del lugar, si hay algún despoblado y los términos colindantes, sin distancia ni rumbos, su valor es prácticamente nulo. En el extremo opuesto se hallan las que responden a las 15 cuestiones con datos copiosos, detallada relación de pueblos y accidentes físicos, situación y distancia en leguas, especificando a veces que equivalen a horas de camino. Entre ambos tipos se encuentran las intermedias, con toda clase de matices que sería demasiado prolijo enumerar.

Los «mapas» remitidos. A las contestaciones se adjuntan, en proporción muy variable según las comarcas, los llamados» mapas» de los corresponsales; tal calificación, habitual como genérica para esos dibujos, es optimista en exceso, hay pocos de factura regular, casi siempre son elementales representaciones, aunque de cierta claridad en ocasiones, muchas veces simples croquis más o menos acertados y bastantes muy burdos, como se lamentan los autores, algunos encuestados se excusan, otros simplemente no los hacen. Los minuciosos corresponden generalmente a las relaciones más precisas, pero también, a veces, a las breves, cifrando en el mapa el detalle de la contestación. También los hay sueltos, sin carta, perdida sin duda o descolocada.

Ante tal variedad, según los conocimientos y habilidad de sus autores, sería preciso un estudio muy detallado para establecer grupos con exactitud, aquí nos limitamos, como ejemplo, a los publicados de Valencia, Albacete, Asturias y Extremadura (en ésta también los del original); la muestra es, ciertamente, muy pequeña, pero ahora sólo intentamos presentar un avance. La exactitud es mayor, lógicamente, en los sitios más próximos a la localidad, algunos presentan escala en leguas, a veces los rótulos se disponen en una lista adjunta con números o letras y la mayoría son rectangulares, pocos en círculo; en 
general se sitúa arriba el norte, otras veces el levante, etc. Normalmente se refieren sólo a la localidad y pueblos colindantes que se indican con casas en perspectiva e iglesias, a veces también algunos más alejado; son pocos los de más amplitud, comarcal o incluso mayor. Según los tipos llevan también ríos, indicación de sierras (representación muy tosca), a veces símbolos de vegetación o nombres de cultivos, en pocas ocasiones los caminos o los supuestos límites de los términos. Los rótulos, casi todos en cursiva y a veces de difícil lectura, van en el dibujo, pero a veces se añaden letras o números de una lista al margen o en el texto.

Incluimos algunos ejemplos aunque la reproducción resulta bastante confusa por la baja calidad del original y la necesria disminución aquí, sólo tratamos de dar una idea.

Para nuestro fin los reunimos provisionalmente en seis grupos, cinco de ellos de peor a mejor factura y representatividad; añadimos un sexto de planos urbanos: $1 .^{\circ}$ Disposición simbólica, más o menos tosca, en sentido radial según los rumbos, de unos rótulos con los nombres de los pueblos y leguas de distancia (fig. 1) ${ }^{8} .2 .^{\circ}$ Contenido análogo de rótulos, pero con dibujo de radios rectos, en estrella más o menos regular. $3 .^{\circ}$ Bocetos muy burdos y variados (fig. 3), simples o abigarrados, con los pueblos, ríos, sierras, etc., a veces auténticos garabatos, en algún caso con líneas rectas como un esquema geométrico, en otros curvas encerrando los términos, a veces como un empizarrado, etc. $4 .^{\circ} \mathrm{Re}-$ presentación más veraz, con los pueblos y accidentes. En ocasiones, sobre todo en llanura, se añaden líneas rectas de puntos desde la localidad a las otras, recordando al tipo segundo. $5 .^{\circ}$ Son pocos los dibujos que se asemejan a un verdadero mapa (fig. 5), según los casos sencillo o abigarrado, local o comarcal. 6. ${ }^{\circ}$ Tipo especial aparte son las representaciones diversas limitadas a la localidad y sus afueras, con plano muy tosco, dibujo simbólico de casas y algún edificio notable. En ciertos casos corresponden también a un lugar de los anteriores.

Solamente los dibujos del tipo $5 .^{\circ} \mathrm{y}$ algunos del $4 .^{\circ}$ podrían ser empleados directamente por López; en todos los demás casos necesitaba transformarlos en croquis propio, claro y de factura uniforme, como veremos a continuación.

8 Corresponden a Extremadura según el original de la Sección de Manuscritos de la Biblioteca Nacional. Agradecemos las facilidades para su consulta y reproducción. 


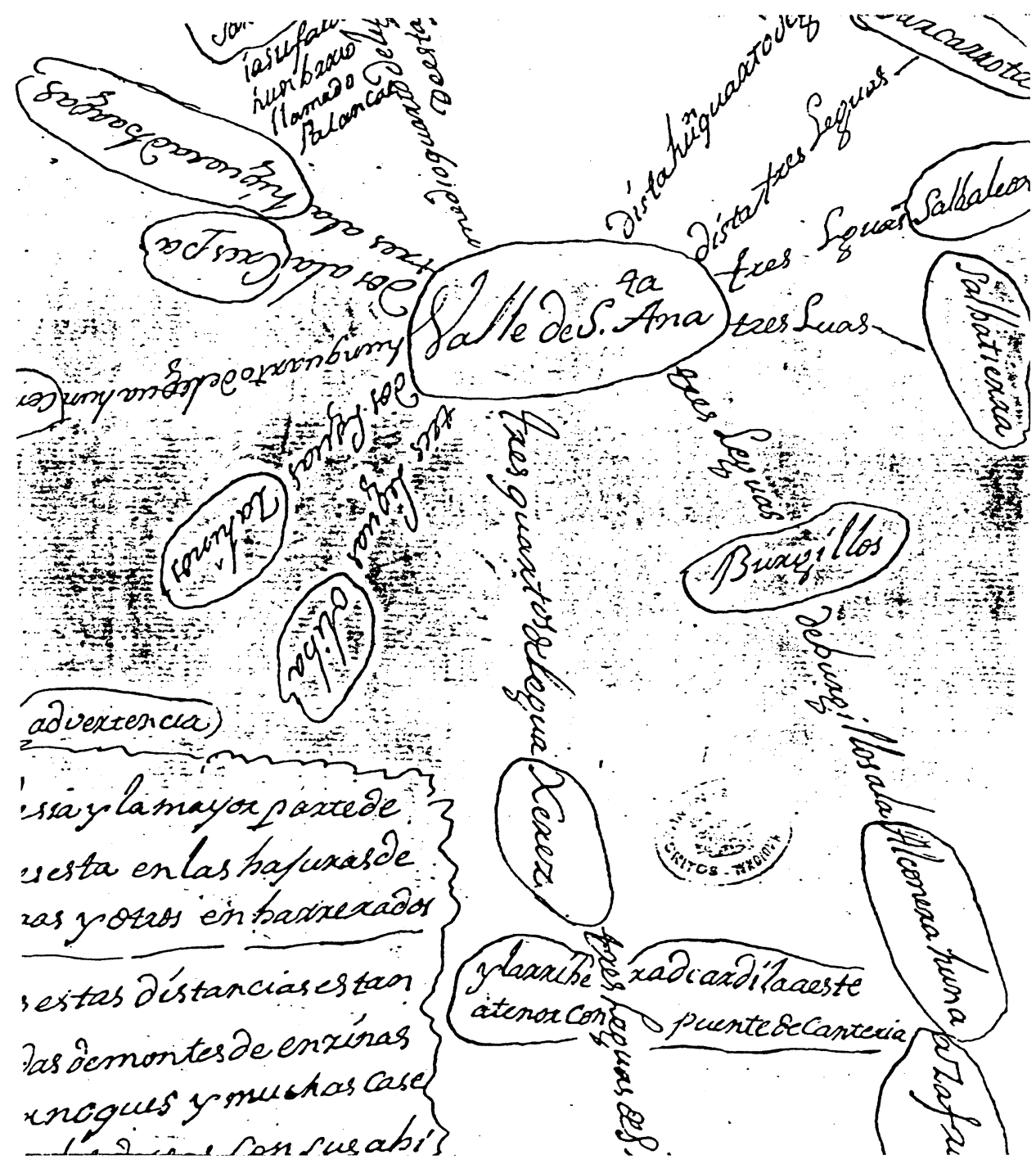

Figura 1.-Valle de Santa Ana (Badajoz). Representación simbólica radial, tipo 1. ${ }^{\circ}$, indicando leguas (Biblioteca Nacional, Manuscritos). 


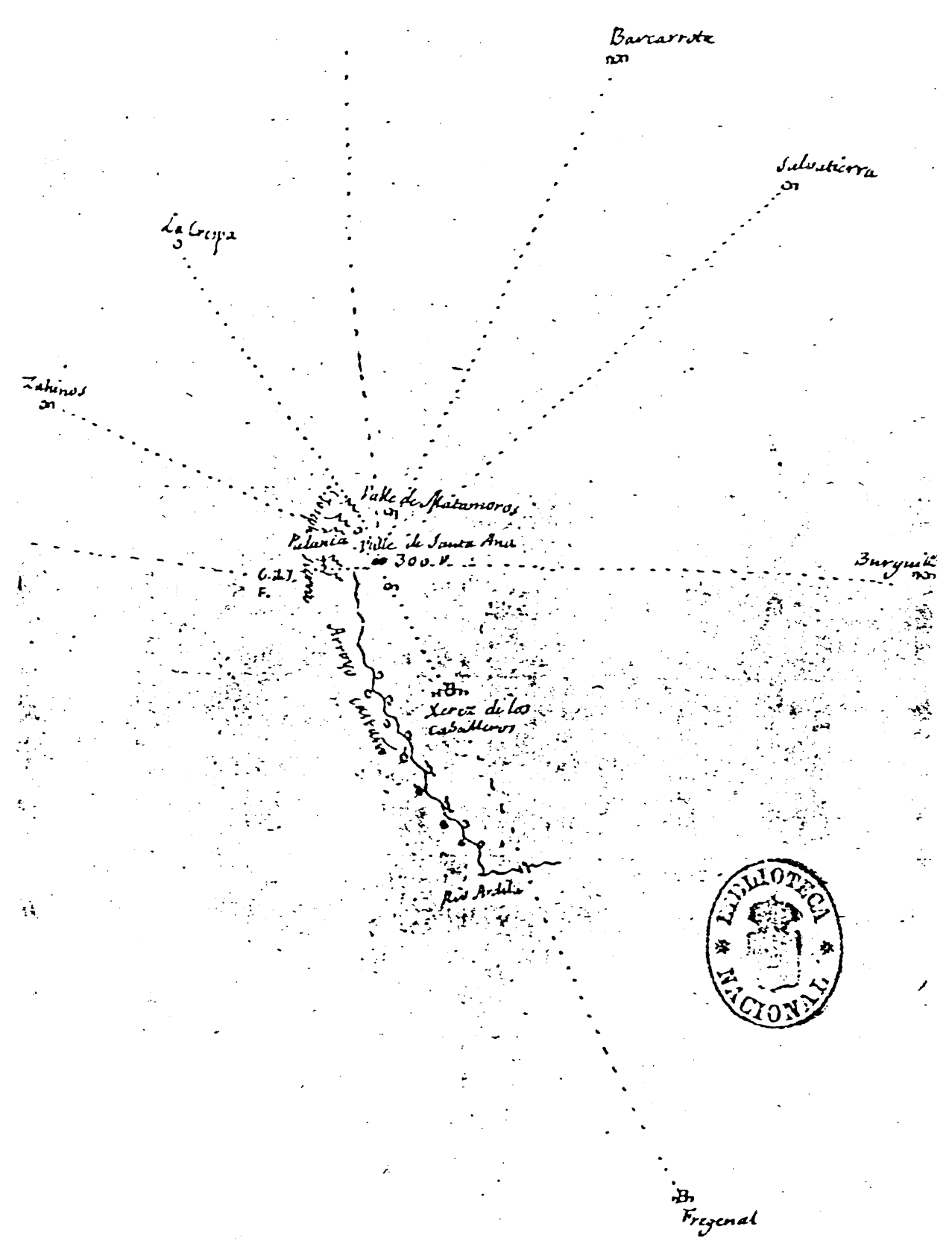

Figura 2.- Valle de Santa Ana (Badajoz). Croquis de López según el "mapa» anterior y la respuesta (Biblioteca Nacional, Manuscritos).

$-691-$ 


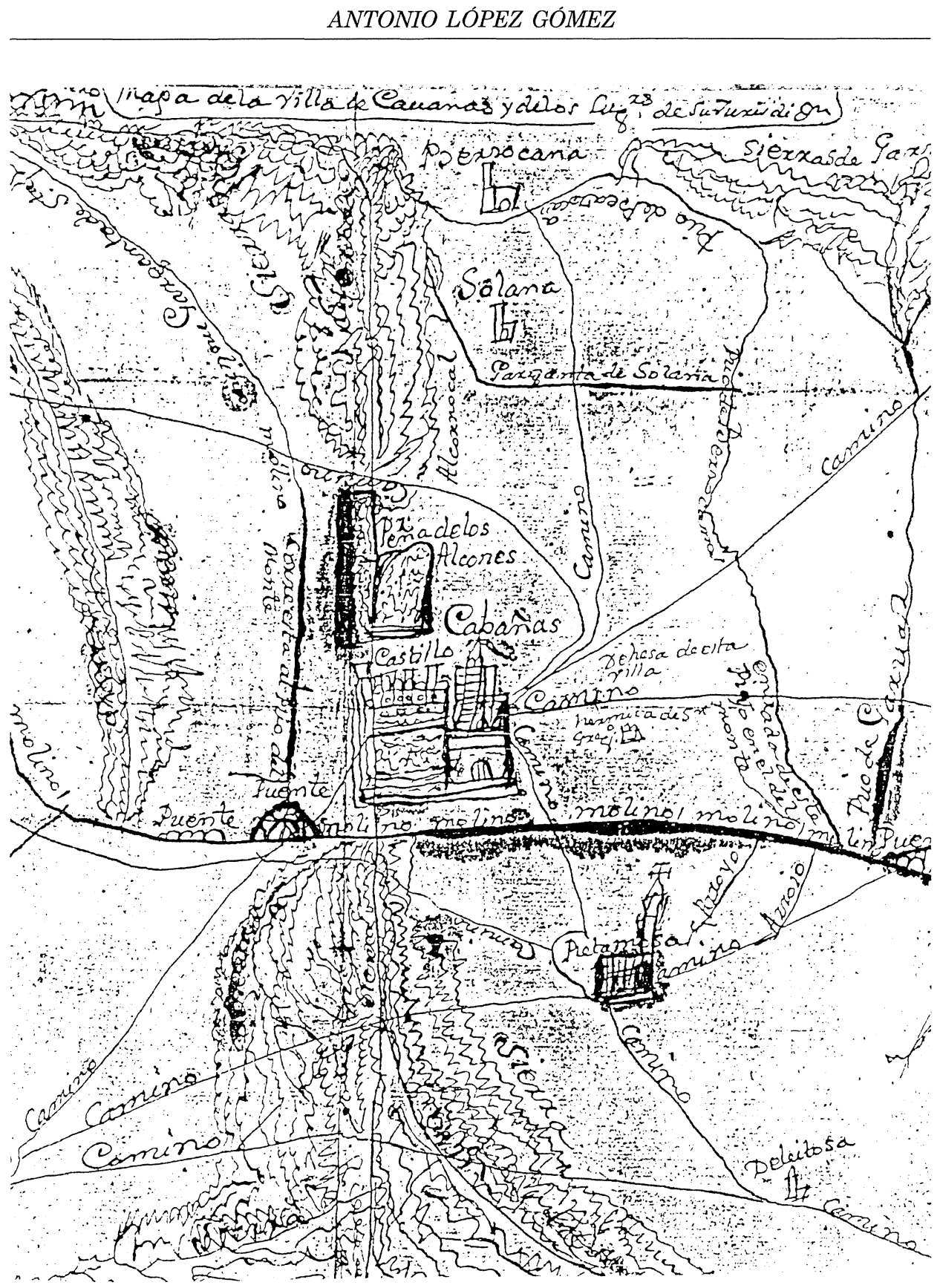

Figura 3.-Cabañas (Cáceres). Croquis tosco remitido, tipo $3 .^{\circ}$, el $N$ abajo (Biblioteca $N a$ cional, Manuscritos). 


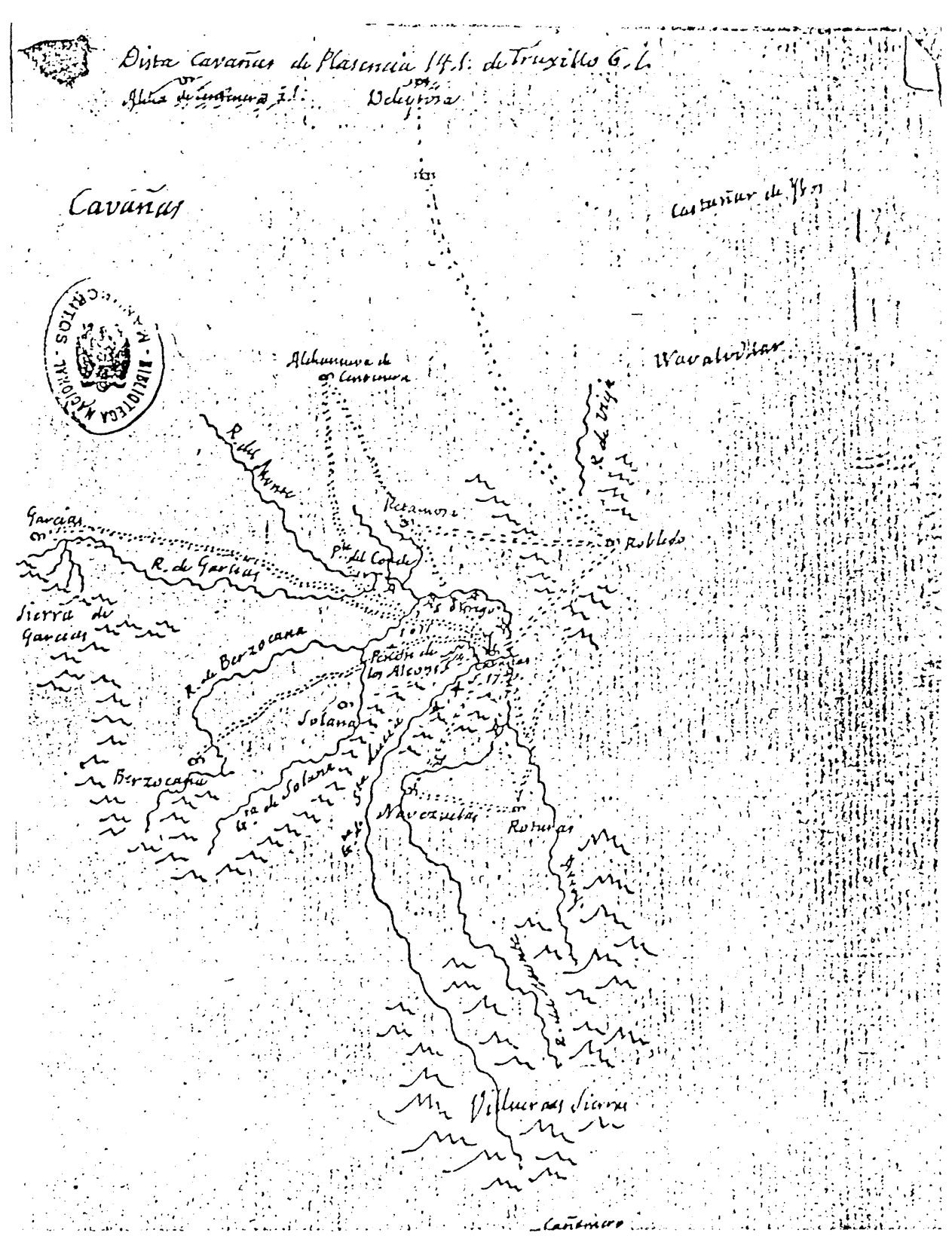

Figura 4.-Cabañas (Cáceres). Croquis de López, según el «mapa» anterior y la respuesta; escala del original en leguas (Biblioteca Nacional, Manuscritos). 


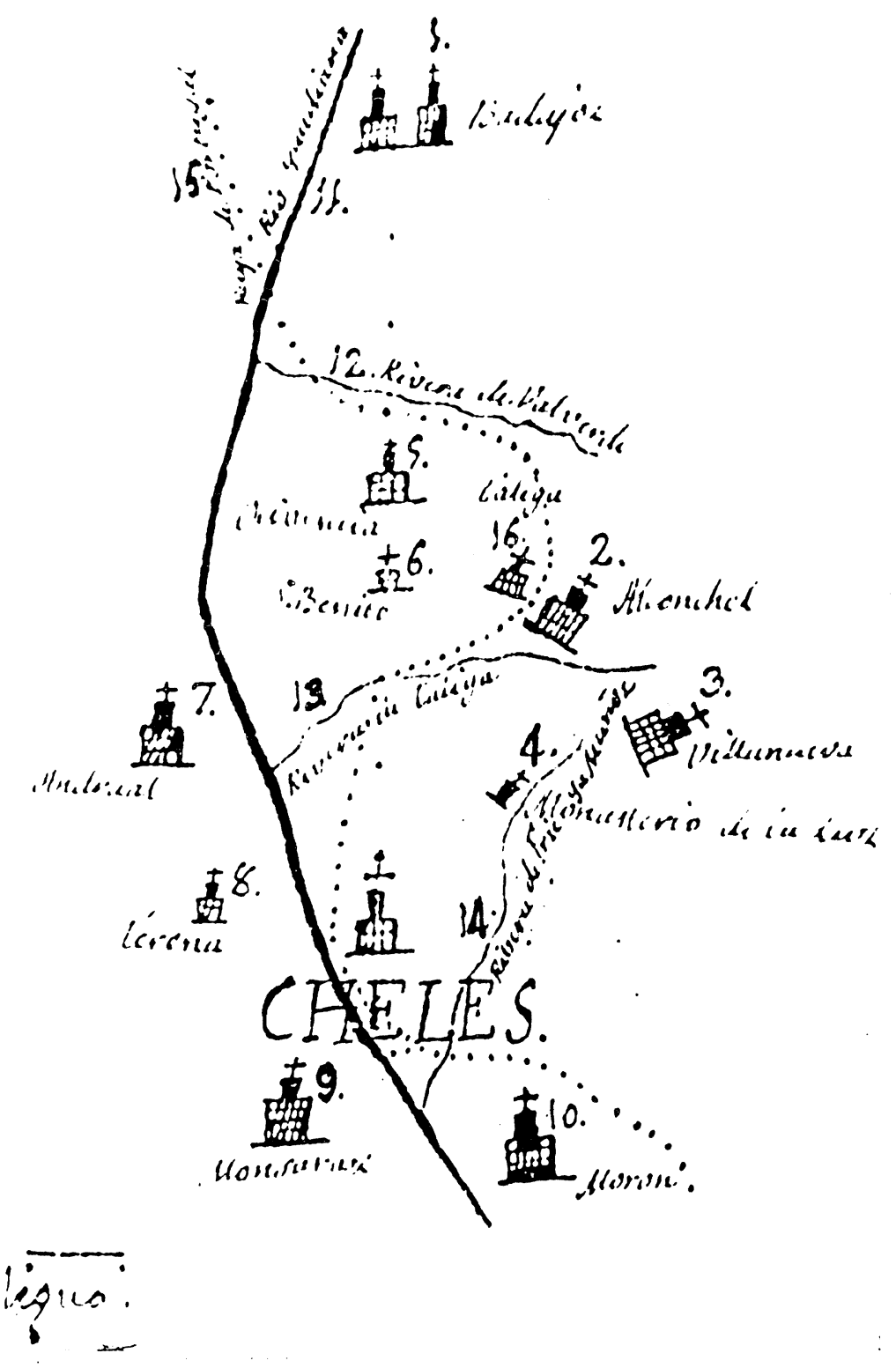

FIGURA 5.-Cheles (Badajoz). Croquis remitido de cierta calidad, tipo $5 .^{\circ}$; hay también croquis de López (Biblioteca Nacional, Manuscritos).

$$
-694-
$$


Los croquis de López. Otro aspecto absolutamente fundamental son los croquis trazados por el propio López y añadidos a las respuestas, sin embargo muchas veces se omiten por los comentaristas ya que exigen la consulta de aquéllas y no figuran o no se especifican en algunas publicaciones de ellas; además ha de subrayarse que no debe haber en todas las provincias, probablemente faltan cuando la edición del mapa es anterior (es cuestión a investigar), al menos así ocurre en Albacete por esa razón. Aunque el resultado último sea totalmente similar, responden, como ya se ha apuntado, a dos casos diferentes, a menudo no señalados pero de notoria importancia: a) según dibujos remitidos; b) según interpretación del propio López, éstos son mucho más numerosos que aquéllos en las provincias estudiadas.

La factura es uniforme y característica (figs. 2, 4, 6, 7 y 8). Tomando como centro la localidad de referencia traza líneas radiales de puntos según los rumbos principales y secundarios, situando los pueblos (en ocasiones también conventos, ermitas, etc.) mediante un pequeño símbolo y a la distancia requerida, según escala en leguas y cuartos representada en el borde inferior de la lámina, por ello muchas veces se pierde en las reproducciones; el dibujo a escala es fundamental para su empleo posterior en el mapa de conjunto. Hecho muy distinto es que las distancias son mera estimación por sus comunicantes, en ciertos casos éstos dicen que las leguas equivalen a horas de camino y alguna vez se especifica que es en caballería o incluso ésta con carga de diez arrobas en Cuevas de Vinromá (Castellón) y allí se dice que la distancia es menor si se mide por la visual u horizontal; en el mapa de Valencia de 1762 una de las escalas está en horas de camino de 20 al grado. También los rumbos son señalados a ojo, sólo en algún caso se menciona observación con brújula, como en Cinctorres (Castellón). Ambos hechos darán lugar a notorias inexactitudes tan subrayadas por los comentaristas, sin embargo, en bastantes ocasiones los resultados son sorprendentes con tan rústicos materiales y revelan la gran pericia de López.

Se incluyen todos los ríos y arroyos posibles, aunque sean tramos muy cortos, con sus puentes, así como lagunas, en realidad más bien charcas, por ejemplo en Extremadura. Pocas veces vegetación de monte. Las sierras, uno de los más serios problemas de representación en su época y también mal resuelto en los mapas definitivos, se indican de manera tosca y puramente simbólica mediante ángulos 
dentellados. En pocas ocasiones figuran tramos de caminos importantes. La rotulación es en letra cursiva y diminuta, aun más empequeñecida en reproducciones y, en numerosas sitios, difícil de leer si no se tiene idea previa por el texto.

En bastantes casos tales croquis se basan en los dibujos recibidos, pero con añadidos o correcciones según el texto (figs. 3-4); en la

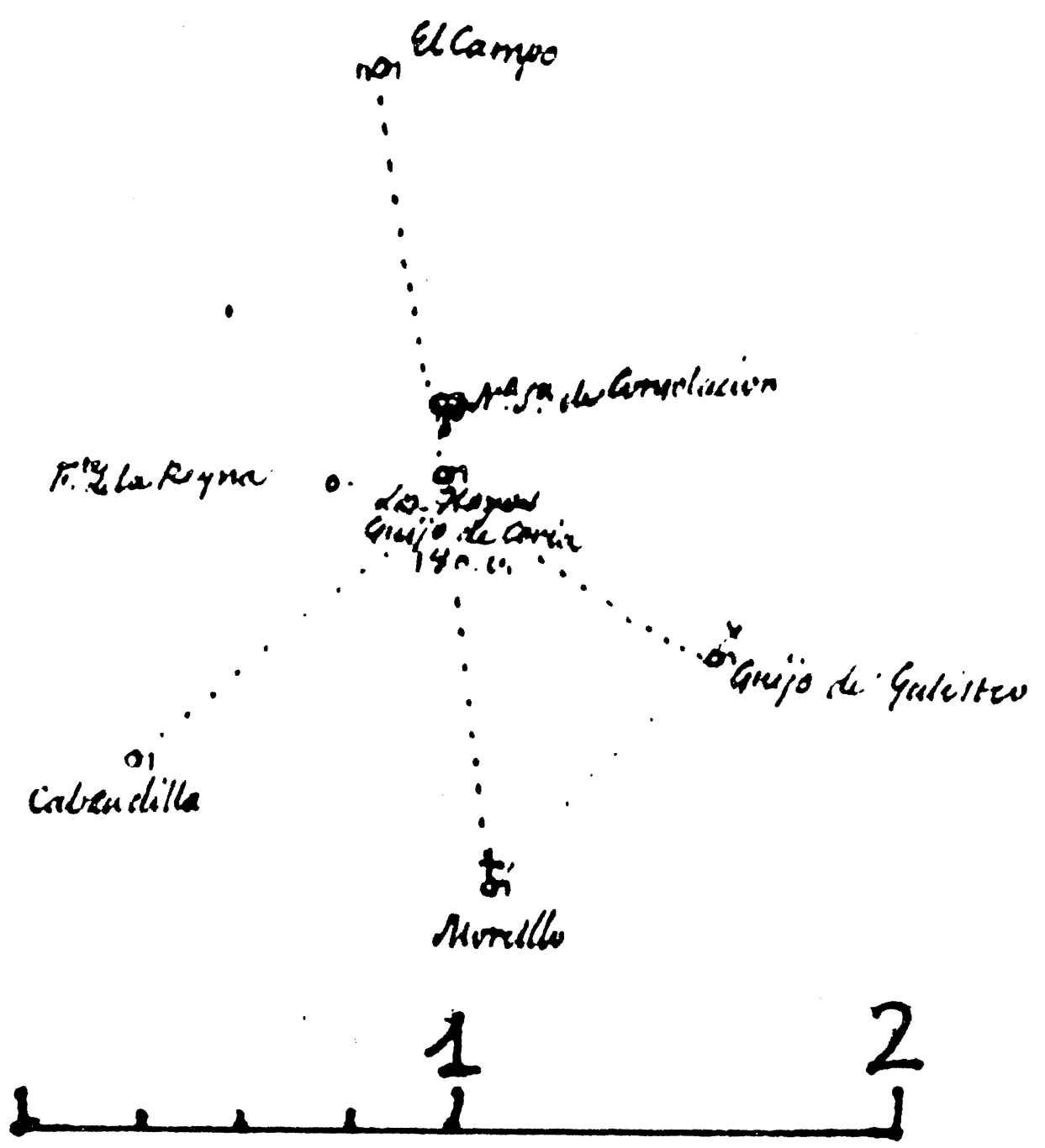

Figura 6.-Guijo de Coria (Cáceres). Croquis de López según los datos de las respuestas, tipo simple; escala del original en leguas (Biblioteca Nacional, Manuscritos).

$-696-$ 
mayoría la transformación es profunda y revela gran trabajo y habilidad, como ya hemos comentado. Pero más aun los otros, más numerosos, ya que lo corriente es que no haya borrador remitido y tenga que acudir a la interpretación directa de los textos (figs. 6, 7 y 8), logrando resultados a veces sorprendentes; la tarea es ardua pero López estaba avezado a ella como buen cartógrafo de gabinete. Las respuestas más detalladas y precisas permiten los croquis mejores, lógicamente, pero también los realiza con las medianas e incluso con las breves, aunque a veces sea un dibujo muy simple, únicamente con

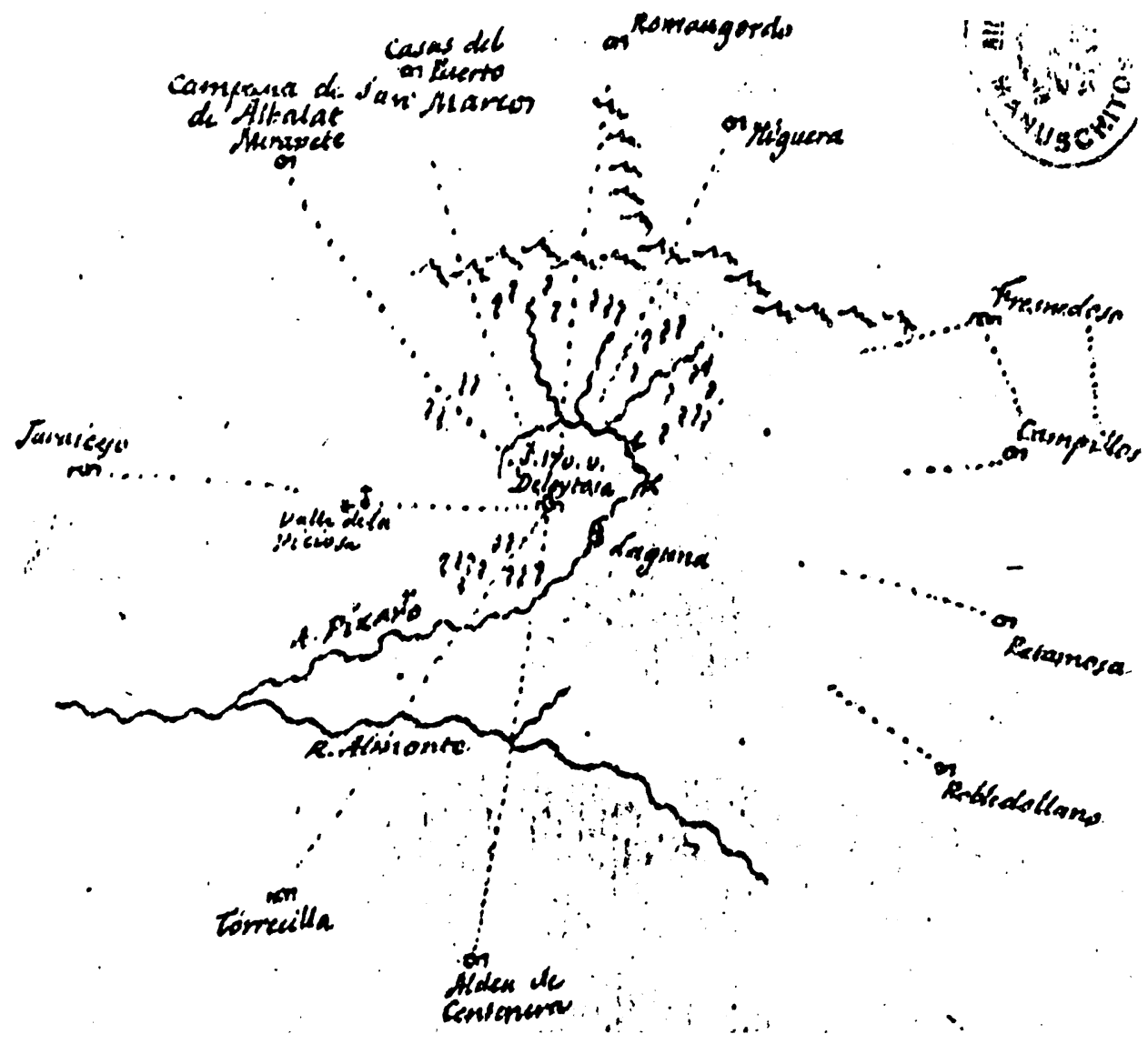

Figura 1.-Deleitosa (Cáceres). Croquis de López según los datos de las respuestas, tipo medio (Biblioteca Nacional, Manuscritos). 


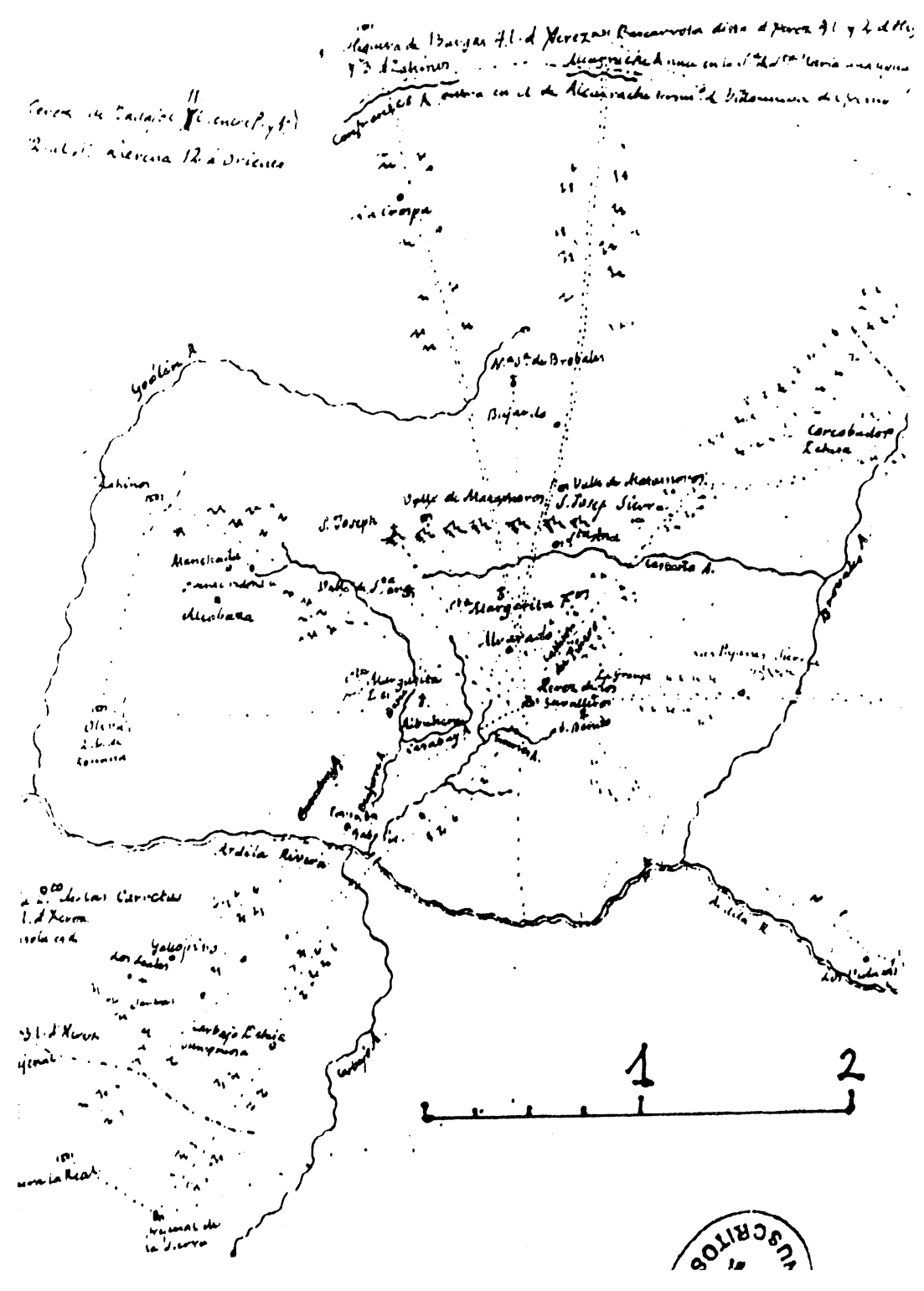

Figura 8.-Jerez de los Caballeros (Badajoz). Croquis de López según datos de las respuestas, tipo extenso, escala en leguas (Biblioteca Nacional, Manuscritos).

$$
-698-
$$


cinco o seis localidades alrededor, o incluso sólo un par de ellas y algún tramo de arroyo.

En cualquier caso es frecuente percibir en sus croquis pueblos mejor situados en los rumbos secundarios que lo señalado en los borradores recibidos o en los textos, en los cuales lo habitual son sólo cuatro direcciones, o bien otros arreglos; ello sólo es posible mediante su propio mapa general, sin hay edición anterior, $u$ otras fuentes en caso contrario, es una cuestión que merecería investigarse.

La utilización de estos croquis en sus mapas definitivos se percibe bien en detalles de correcciones o añadidos, por ejemplo, en las segundas ediciones de Extremadura y Valencia. No obstante hay veces en que un borrador recibido o un texto y su croquis contienen errores que López no puede conocer o no subsana y en la segunda edición de su mapa aparece una nueva inexactitud, en otro trabajo ya señalamos algún ejemplo en los alrededores de Alicante (21).

\section{El Diccionario}

Nos referimos muy brevemente a esa cuestión, ya apuntada, únicamente por su actualidad en la época, como ha estudiado Capel (8). La misma Real Academia de la Historia trató de realizar uno grande, del cual sólo se publicaron los volúmenes de Navarra y Vascongadas; para ello se hizo acopio de mucha documentación, por ejemplo, tal fin tendrían los resúmenes de Respuestas generales del Catastro de Ensenada y las Relaciones Topográficas de Felipe II, trasladándose temporalmente el original escurialense de éstas para una copia, como ya se dijo; tan genuino modelo de encuesta sería conocido por López. El cuestionario de éste es, sin duda, de doble finalidad: cartográfica y así lo utilizó, pero también es evidente la otra, para un diccionario y así lo reconocen todos los autores; no se entienden, de otra forma, nueve de las quince preguntas, sobre población, producciones, montes, ferias, enfermedades, sucesos, etc., innecesarias para la cartografía, ya que es inconcebible en aquella época la pretensión de mapas temáticos sobre tales aspectos.

Una prueba sería la concreta indicación del propio López en la carta-circular enviada con el interrogatorio; en ella apunta el doble fin: para la ejecución de «un Mapa y descripción de esa Diócesis» y

$$
-699-
$$


para «desterrar de los Mapas extrangeros, de las descripciones y Geografías, muchos errores que nos ponen: unos cautelosamente, otros ocultando nuestras producciones», ya reproducida por Marcel (28, nota p. 163) y otros (facs. 35 , p. 350).

Otra muy probable se puede añadir en la $2 .^{a}$ edición del mapa de Extremadura (1798), en una «Nota» en el rincón inferior derecho, se excusa de no incluir por falta de espacio los nombres de los comunicantes, como había prometido y añade: «se dexará para un análisis que de este papel y otros estoy haciendo»; parece explícita alusión al ámbito de los mapas y el fin descriptivo, más dudoso es el comienzo real de la tarea («estoy haciendo»), quizás algún borrador inicial.

A la preparación de esa labor deben referirse, posiblemente, las listas de lugares incluidas en cabezas de vicarías y partidos extremeños, o mejor aun indicando junto a los nombres las palabras «descripción, mapa», como material disponible seguramente, en los obispados de Badajoz y Coria (4, pp. 82 y 167-68), pero no en el de Plasencia.

Lo más probable es que, absorbido por la intensa labor cartográfica, no pudo López dedicarse al Diccionario en la medida deseable y lo pospuso, o se desanimó ante la abrumadora tarea y la ingente acumulación de material tan diverso, muchas veces de baja calidad, en el cual, por otra parte, había notorios huecos en ciertas comarcas.

Harían el diccionario después, en el XIX, Miñano y, con mucha mayor amplitud Madoz, éste en relación directa con los mapas de Coello; se cumplía así lo que probablemente fue la doble idea de López quien, de haberla realizado, hubiera sido un auténtico pionero.

\section{Las respuestas y los mapas definitivos. Cuatro ejemplos}

Según todo lo expuesto parece posible avanzar una consideración más precisa y matizada sobre el empleo de las respuestas y el llamado a veces «método de Tomás López», objeto de opiniones tan diversas como las apuntadas; lo haremos con tres ejemplos detallados, Albacete, Extremadura y Valencia y unas notas sobre Asturias; en ellos parecen mostrarse las cuestiones fundamentales, sin embargo el estudio de todo el «Diccionario» depararía probablemente otras novedades y precisiones. 
Es evidente que en la realización de los mapas de España sólo hay tres posibilidades en relación con el interrogatorio y de resultados distintos, aunque en realidad la diferencia, no sea excesiva: 1) Mapas editados con fecha anterior a las respuestas. Es obvio que sólo pudo emplear otras fuentes: mapas publicados o manuscritos anteriores, obras diversas o algunas noticias sueltas de «los naturales», como suele indicar en la cartela según ya apuntamos. No se trazaron según su «método», supuesto habitual generalmente, de utilizar también datos sistemáticos recibidos de los pueblos. 2) Mapas posteriores a las respuestas, detallando éstas o no según los casos. Las emplearía, además de las otras fuentes, de manera más o menos intensa a tenor de su cantidad o calidad y, en general, elaborando previamente sus propios croquis, según los recibidos o directamente interpretando los textos. Sólo en este segundo caso pudo seguir el método considerado general. 3) Mapas realizados después de cierto número de contestaciones; otra parte son posteriores. En este caso intermedio únicamente podría utilizar las primeras.

Cuestión aparte, por ahora sin solución ya que exigiría considerar en detalle toda su obra, es cual ha sido el sistema más frecuente.

Otro asunto, que no abordamos aquí, son los mapas de territorios de las órdenes militares, que tenemos en estudio. En la Academia de la Historia están reunidos en un atlas facticio, ya citado, son poco utilizados y con muchos más detalles, dada la mayor escala. En ellos no cita López fuentes; es de suponer que el Consejo de Ordenes, para el que los hizo, con una comisión presidida por Jovellanos (9, p. 156; 33 , p. 103), le facilitaría la documentación (mapas, si existían, croquis, relaciones), con más pormenor y más completa, puesto que dicho organismo la podría obtener directamente en sus diversos territorios.

Para examinar con cierto detalle la relación entre el interrogatorio, los croquis de éste y los mapas definitivos, contamos, afortunadamente, con varios de éstos sólo con edición anterior a las respuestas y otros con dos, antes y después, aparte de aquellos con única posterior que no consideramos ahora. Como ya se dijo, tomamos como muestra parcial pero seguramente significativa, cuatro ejemplos con relaciones ya publicadas lo que facilita considerablemente la labor. Así ocurre en el primer caso con los mapas de La Mancha (1765), Cuenca (1766) y reino de Murcia (1768), mientras que son de 
1786-89 las relaciones de los sectores que formaron la nueva provincia de Albacete, por tanto no se pudieron utilizar y tampoco hay croquis propios de López. En cambio, hay dos ediciones en los mapas de Extremadura (1766 y 1798) y Valencia (1762 y 1788), entre ambas se hizo el interrogatorio y hay croquis de López, este material se pudo emplear en la segunda edición, como efectivamente se comprueba. En otros trabajos se exponen con detalle los resultados obtenidos en el estudio concreto de tales casos $(22,23,24)$, ahora sólo apuntamos los rasgos esenciales.

Avanzamos también algunas notas sobre Asturias, que estamos estudiando, ya que responde al caso intermedio con relaciones antes y después del mapa de 1777 . No nos referimos a las actuales provincias de Sevilla y Almería porque las ediciones no incluyen dibujos y exigen la consulta del original, aun no realizada.

La importante cuestión de ausencia real de contestación no puede solucionarse porque ignoramos la lista completa de peticiones y sólo hay pocas cartas indicando negativa, en general por enfermedad, traslado reciente, etc.

En una encuesta de tal volumen y vicisitudes pueden ser numerosas las pérdidas posteriores, lo que afectaría a nuestras consideraciones. Solamente se pueden computar, comparando con las respuestas conservadas, cuando López da puntual relación de las que emplea como ocurre en varios casos, concretamente en Valencia; allí al menos no tiene gran importancia como se indica después. No podemos juzgar todavía en otros casos con lista general, ya citados, pero sin edición y ha de estudiarse el manuscrito original.

Albacete. Como es sabido esta provincia moderna, de la división de 1833, se forma con parte de las antiguas antes citadas; las relaciones correspondientes a esos sectores son de 1786-89, salvo una de 1773, es decir, veinte años posteriores a los mapas de López de aquéllas (1765-68), como se ha indicado antes. Las 38 respuestas conservadas y publicadas por Rodríguez de la Torre y Cano Valero (35), suponen una cobertura del $44 \%$ sobre los 86 municipios actuales, pero con diferencias territoriales considerables; hay notoria concentración al NE, en la zona del Júcar, otras secundarias en el SE (comarca de Hellín) y SW (sierra de Alcaraz); en cambio existen amplios espacios manchegos y en el S (alto Segura y Mundo) vacíos o poco menos, como detallamos en otro lugar (22). 
Cerca de la mitad de la relaciones contienen «mapas» remitidos (15 en total, aunque tres de ellos muy malos y por ello no se reproducen), la agrupación es todavía mayor puesto que, salvo dos, todos corresponden al NE; pertenecen a los diversos tipos ya señalados. No hay ningún croquis de López, ni sobre esos borradores ni sobre el texto; sin duda pospuso tan prolija labor hasta una posible segunda edición no realizada.

En cualquiera caso, aunque hubiera contado previamente con las respuestas y croquis, ni los huecos de información ni el carácter de ésta le hubiesen permitido que fueran la base inicial del mapa definitivo. Se comprueba especialmente en el caso de los ríos; el curso del Júcar aun puede dibujarse aproximadamente en la zona del codo, con los «mapas» enviados de Villalgordo de Júcar y Tarazona, no con el de La Roda, en el cual no figura el río (!), o aguas abajo, junto con el Cabriel, con los de Mahora y Villa de Ves; por el contrario no hay ninguno en que aparezca el Segura.

Reino de Valencia. Resumiendo lo detallado en otro trabajo (24), señalaremos que hay dos ediciones del mapa y entre ambas se realiza el interrogatorio. Como ya indicamos antes, en la primera de aquéllas, de 1762, cita como fuente esencial el mapa de 1693 del jesuita Francisco Cassaus y alude a otros de Pedro Texeira y de Carlos Denauy (costa sur, manuscrito) pero rechaza los de Nolin e Incelin; asimismo se refiere a las coordenadas de la capital.

En la segunda edición, de 1788, además de mencionar las fuentes usadas en la anterior, añade «los expresados mapas, descripciones y noticias remitidos por las personas que se nombran en éste prólogo», con larguísima lista que ocupa todo el cuadrante SE de la lámina, detallando todos los nombres y lugares de los colaboradores, esencialmente sacerdotes, así como otros mapas impresos o manuscritos. Efectivamente, es en esta edición en la que emplea, como novedad, las respuestas al interrogatorio y sus croquis.

Como ya se apuntó, se encontraban en un manuscrito aparte de los volúmenes de la Biblioteca Nacional, lo poseía Castañeda, quien lo publicó (10) y hoy está en paradero desconocido. Reprodujo croquis de los curas y también de López (a veces con atribución errónea), pero sólo los de éste cuando había también de aquéllos, los cuales ahora ya no es posible analizar ni en calidad ni en número. Incluye además mapas de otros autores y épocas que pueden inducir 
a confusión. Aquí seguimos las tres provincias modernas, por separado, como hace Castañeda, pero de $\mathrm{N}$ a S.

En la de Castellón hay sólo respuestas de 14 sitios, entre 177379 , muy pocas para los 135 municipios actuales, el 10,3\%. Un par de ellas son muy detalladas, otras intermedias y dos inútiles, que serían muy importantes, Castellón y Morella, con largas listas de pueblos pero sin rumbos ni distancias. La distribución es muy irregular, 9 en la zona media meridional, dispersas las otras 5 , por tanto en blanco la mayor parte del territorio. Hay 5 dibujos de colaboradores y otros dos se citan pero no reproducen, solamente hay tres de López . Llama la atención en uno de los primeros, el de Cinctorres, la indicación de que lleva meridianos y paralelos según un mapa de España de Matheo Sentir y, sobre todo, que en la mayoría de los pueblos la situación está «averiguada con la brújula y convinado con cuadrante».

Similar es el caso de la provincia de Valencia, con 52 respuestas para 263 municipios sería el $20 \%$, pero 26 carecen de valor, con lo que se reducen a la mitad, al $10 \%$. Se concentran en la Ribera del Júcar, con 39, pero la mayoría son inútiles; las 13 restantes se hallan dispersas, tres en los alrededores de la capital, ocho más en el W y NW de la provincia. Se halla en blanco todo el extenso SW, ciertamente comprende la vasta plataforma del Caroche, casi despoblada, pero tampoco hay de los valles marginales; pocas en el valle de Montesa, solamente dos en las sierras meridionales y otras dos en la costa. Se mencionan cinco croquis de curas no reproducidos y 10 de López, pero uno atribuido a éste, el de Alcira, no es de él. En la Ribera del Júcar varios se solapan y también tres en las costa norte, desde Nules hasta el S de la Albufera.

Las respuestas de Alicante están fechadas entre $1775-80$ y la cobertura es analóga, 18 para 140 municipios, el $13 \%$. La distribución también es muy irregular, 11 en el NE, en La Marina y sierras aledañas, diseminadas las otras y con grandes huecos; 12 tienen suficiente detalle para que López haga croquis, la mayoría corresponden al NE y además empalman entre sí, desde Denia hasta la capital.

En cuanto a las relaciones perdidas (listas, descripciones, mapas) que aquí pueden computarse, no son muchas más según las que menciona López como empleadas y sólo alteran levemente algún vacío, con ciertas diferencias en las tres provincias. En la de Castellón cita en total 32 noticias, sin incluir dos publicadas (Onda y Espadilla), 
con ellas serían 34 lo que supone el $25 \%$ de los municipios actuales, todavía pocas en conjunto; como en la edición figuran 14 las perdidas son 20, parecen muchas pero en realidad sólo se rellenaría algo el centro y norte con 10 respuestas más y sobre todo el $\mathrm{S}$, con otras 10 , pero ésta zona ya bastante bien cubierta con las publicadas.

La provincia de Valencia es un caso muy especial, están editadas 52 pero sólo se especifican en el mapa 30 , sin duda porque muchas de aquéllas, en la Ribera del Júcar, son inútiles como ya se indicó. Las 30 citadas, añadiendo las tres de Requena, Camporrobles y Villargordo de la provincia moderna, suponen sólo el 10,5 \% de los términos actuales; faltarían 9, algunas de interés por corresponder al vacío del SW.

Por último, en Alicante, se mencionan 22, con Villena y Sax de la división moderna serían 24 , el $15,7 \%$ de los municipios de hoy; faltan 8 , de especial interés alguna del S. Además un mapa del obispado de Orihuela y otro de Jorge Juan. Es obvio, por la fecha, que no pudo utilizar las respuestas en el primer mapa del reino, en cambio sí en el segundo, donde las cita específicamente y se comprueba con facilidad, por ejemplo en la Huerta de Alicante (21), aunque a veces con algún error nuevo. En conjunto, sin embargo, incluyendo las perdidas, el uso sería sólo para correcciones y añadir detalles, a veces importantes, pero debido a sus caracteres y a los notables vacíos resultan insuficientes como base para un mapa nuevo y original.

Extremadura. Hay dos ediciones del mapa de López, la primera es de 1766 y en ella dice haber utilizado, como ya se indicó, el mapa manuscrito de Luis Josef Velázquez, el del maestre de campo Luis Venegas y noticias de naturales, sin especificar. Ya aludimos antes, al referirnos a Marcel, a algunas recibidas por entonces y en el caso de Guadalupe se pueden añadir varias más, como detallamos en otro trabajo (23), una es de 1765 contestando a López sobre una «minuta» con dudas y prometiendo una noticia «mapeada» con meridianos y paralelos (3, p. 226); en cambio, la referencia al «ynterrogatorio" recibido, el general, es ya en otra carta de 1787 y la relación concluye recomendando para más detalles el mapa de las Sierras de Guadalupe, impreso por el propio López en 1781 (3, p. 226), lo que es una incongruencia. Los primeros casos, según ya apuntamos, deben ser aislados y las respuestas generales, salvo alguna de 1782, son entre 1785-98, es evidente que sólo las pudo em- 
plear en la 2. ${ }^{\text {a }}$ edición. Ésta es de 1798 y en ella se disculpa, como ya se apuntó, por no incluir la lista de colaboradores debido a la falta de espacio.

En la publicación de Barrientos (3) se citan numerosos «mapas» y «croquis», sin precisar autor, los primeros deben ser, en su mayoría, remitidos por los colaboradores, los otros, de López; se reproducen bastantes, de ambos tipos, incluso de la misma localidad y corresponden a los grupos ya mencionados; la consulta del original nos ha permitido comprobar cómo, entre los de López, muchos más son interpretación del texto que dibujados según borrador remitido.

La cobertura de relaciones es buena en general, el $53 \%$ para los 380 municipios actuales, pero muy desigual en las dos provincias modernas y dentro de ellas. Es mejor en la de Cáceres, con 141 para 218 municipios, el 64,6\%, y se concentran en el Tajo y afluentes del norte, donde también son numerosos los pueblos, de manera muy notable entre los ríos Tiétar y Alagón; también hay bastantes a lo largo del Tajo, en la parte oriental y en la margen $\mathrm{N}$ de la occidental. En cambio disminuyen al $\mathrm{S}$ del río Almonte, también los pueblos, salvo en la sierra de Montánchez con bastantes. Son ya escasas las relaciones en el oeste de la capital y prácticamente no hay en el suroeste (también pocos pueblos).

Solamente tres carecen de valor, en las otras es diverso. No hay dibujo en 14, existe del comunicante en 31 y en éstas y todas las demás se encuentra el croquis de López, 124 en total lo que supone la excelente cobertura del 84 \% de los interrogatorios; además hay numerosas yuxtaposiciones.

En Badajoz el porcentaje de respuestas se reduce al 37,6\%, con 61 para 162 municipios hoy. La agrupación es notable en el SW, ya menor entre el Guadiana medio y el bajo Matachel. Las demás están dispersas, son escasas en el bajo Guadiana y casi en blanco al S del Zújar hasta el Matachel medio y más allá. Únicamente media docena carecen de valor, lo tienen 16 pero sin «mapa» remitido, cuatro sólo poseen éste y en todas las otras hay croquis de López, se concentran también en el SW y en 9 derivan de borrador.

En resumen, con una cobertura de relaciones buena, mejor en Cáceres que en Badajoz, son muy abundantes los croquis de López que le permitirían añadidos y correcciones en la segunda edición de su mapa, como se comprueba en bastantes sitios. 
Asturias. En la edición de M. ${ }^{a}$ J. Merinero y G. Barrientos (29) aparecen relaciones de 43 concejos, aunque en varios casos incluyen también la de alguna otra localidad o parroquia, frente a los $78 \mathrm{mu}$ nicipios actuales suponen una buena cobertura del 55,1 \%; sin embargo, la extensión de algunos y el poblamiento disperso supone notoria diferencia con los espacios antes analizados. Se insertan 15 croquis, de los cuales en dos casos (Candamo y Villaviciosa) son dos del mismo sitio aunque muy distintos y otro es general de Asturias (muy tosco); solamente uno es de López, el de Pravia, todos los demás remitidos y algunos muy burdos. En los textos se citan varios más, Cangas de Onís, Laviana, Proaza y Ribadesella, pero no figuran (¿perdidos?, ¿no publicados?), no se dice si hay otros y llama la atención la ausencia de los del propio López; sería necesaria la consulta del original, que no hemos podido hacer todavía. Tampoco figura la relación de Cangas del Narcea (?), del mismo manuscrito, analizada por Feo Parrondo (14) con una detallada descripción que permite a López hacer un croquis.

Hemos dicho que Asturias es una caso especial intermedio entre los anteriores, efectivamente, las cartas fechadas (algunas no lo están) corresponden a dos etapas distintas; un grupo que no llega a la docena es de 1771-75, salvo una de Grandas de Salime de 1767 (?); el mapa se publica en 1777 y la mayoría de las respuestas son posteriores, de la década de 1790, tambien los dibujos, insistiría López en su interrogatorio pensando sin duda en trabajo posterior.

\section{Conclusiones}

Todos los investigadores han subrayado el peculiar método de Tomás López como "geógrafo de gabinete» mediante la utilización de dos series de fuentes: los mapas existentes, impresos o manuscritos, y las noticias -básicas o suplementarias según los diversos autoresrecibidas por un interrogatorio a numerosas personas, sacerdotes especialmente, así como esquemas o «mapas» locales remitidos también por éstos. Ha de añadirse algo muy importante pero que a veces se omite: con esos esquemas o directamente del texto, López hacía sus propios croquis previos al mapa definitivo. Otra finalidad de las respuestas sería hacer un verdadero «Diccionario Geográfico».

El examen de varias provincias publicadas (Albacete, Oviedo, las 
extremeñas y las valencianas) y los mapas correspondientes nos llevan a diversas conclusiones que precisan ciertos aspectos; la muestra es pequeña, pero seguramente extensible al resto con las modificaciones que sean pertinentes.

1. Hay casos en que las respuestas son posteriores al mapa publicado en edición única, por lo tanto no pudo emplearlas en éste, no son ni básicas ni auxiliares; así ocurre, por ejemplo, en los sectores de las provincias de entonces de La Mancha, Cuenca y reino de Murcia que forman la moderna de Albacete. Hay bocetos de los remitentes, pero no croquis de López, no los pensaría hacer hasta una segunda edición que no realizó.

2. Por la misma razón de posterioridad tampoco pudo emplear dichas contestaciones en el primer mapa de Valencia y sólo alguna noticia aislada en el de Extremadura.

3. Hay muchas respuestas y croquis de Cáceres, menos de Badajoz y pocas de las tierras valencianas; además están distribuidas de forma irregular, con vacíos más o menos extensos, aunque en ocasiones se solapan los croquis cubriendo extensiones mayores.

4. No pudieron servir de base inicial del mapa, pero las emplea en la segunda edición para enmiendas o adiciones, sobre todo mediante los croquis trazados por él mismo que son fundamentales.

5. En algún caso, como Asturias, el mapa se publica entre dos series de respuestas; sólo pudo utilizar la primera.

6. En suma, no puede considerarse esencial la encuesta en el llamado a veces «método de López». No la aplicó en los mapas más tempranos, anteriores a aquélla, sino únicamente en los posteriores y como complemento, a veces importante, para añadidos o correcciones.

\section{BIBLIOGRAFÍA}

1. Antillón, Isidoro: Lecciones de Geografía astronómica, natural y politica, Madrid, Imp. Real, 1804-1806, 2 vols.

2. Id.: Elementos de la Geografía astronómica, natural y política de España y Portugal, Madrid, Imp. Fuentenebro y Cía., 1808, XXXVIII-254 pp.

3. Barrientos Alfageme, Gonzalo: Estremadura por López, año de 1798, estudio y recopilación por... Mérida, Asamblea de Extremadura, 1991, 600 pp. Introducción (pp. 1-13) y Extremadura en la época de López (pp. 23-28) por G. Barrientos; Interrogatorios del siglo xviII. Estudio comparado (pp. 15-21) por M. Rodríguez Cancho; cartas e interrogatorios (pp. 31-594). 
4. Bécker, Jerónimo: Los estudios geográficos en España, Madrid, Imp. J. Ratés, 1907.

5. Beltrán y Rózide, Ricardo: Isidoro de Antillón, geógrafo, historiador y político, Discurso Real Academia de la Historia, Madrid, 1903.

6. CABo Alonso, Angel: «Dos fuentes informativas sobre la geografía histórica salmantina», Homenaje a J. L. Cruz Reyes, Univ. Salamanca, 1990, pp. 43-58.

7. Camarero Bullón, Concepción: «La Planimetría General de Madrid en el contexto de las políticas de conocimiento del espacio y de reforma fiscal», I, pp. 41-80 en Planimetría General de Madrid, Madrid, Ed.Tabapress, 1988, 2 vols.

8. CAPEL, Horacio: «Los diccionarios geográficos de la Ilustración española», Geocrí tica, 1981, núm. 31, 51 pp.

9. Id.: Geografía y matemáticas en la España del siglo XVIII, Barcelona, Oikos-Tau, $1982,389 \mathrm{pp}$.

10. Castañeda y Alcover, Vicente: Relaciones geográficas, topográficas e históricas del Reino de Valencia hechas en el siglo XVIII a ruego de Don Tomás López, con notas, aumentos y comentarios... Madrid, Tip. Revista de Archivos, Bibliotecas y Museos, 1919-24, 3 vols.: I, Alicante-Castellón de la Plana; II y III, Valencia. Publicado en diversos núms. de la citada Revista entre 1916-24.

11. Domf́nguez Ortiz, Antonio: «El reino de Sevilla a fines del siglo xviII según las relaciones enviadas a Don Tomás López», Archivo Hispalense, 1944, 2. ${ }^{a}$ ép., núm. 7-8.

12. Faus Prieto, Alfredo: Mapistes. Cartografía y Agrimensura a la València del segle XVIII, Valencia, Ed. Alfons el Magnànim. Generalitat Valenciana, 1995, 360 pp.

13. Feo Parrondo, Francisco: «Tineo a finales del siglo xviII según el Diccionario Geográfico de Tomás López», Heraldo de Tineo, 1984, 16, p. 13.

14. Id.: «Cangas a finales del siglo xvil según el Diccionario de Tomás López», La Ma niega (Cangas del Narcea), 1993, julio-agosto, pp. 10-12.

15. Fernández Duro, Cesáreo: «Los orígenes de la carta o mapa geográfico de España», Bol. R. Academia de la Historia, 1899, vol. 35, pp. 502-25.

16. Fernandez de Navarrete, Martín: Biblioteca Maritima Española, Obra póstuma, Madrid, 1851, 2 vols. (sobre Tomás López, II, pp. 727-29).

17. Garrigós Pico, Eduardo: «La política cartográfica en España (siglos XVI-XVIII)», pp 35-57, en Historia de la Cartografía Española, Madrid, Real Academia.

17 bis. GAviRA, José: Aportaciones para la Geografía española del siglo xviII, Madrid, Blass, $1932,71 \mathrm{pp}$

18. Id.: Catálogo de la Biblioteca de la Real Sociedad Geográfica, Madrid, E. Soc. Geográfica, 1948-50, 2 vols.

19. Líter MAYAyo, Carmen: «Aproximación a la vida y obra del cartógrafo Tomás López», Catastro, 1991, pp. 21-27.

20. Líter Mayayo, Carmen; Sanchis Ballester, Francisca, y Herrero Vigil, Ana: Cartografía de España en la Biblioteca Nacional (siglos XVI al XIX), Madrid, Biblioteca Nacional, 1994, 2 vols.

21. LÓpez GÓmez, Antonio: «La Huerta de Alicante en el siglo xviı», pp. 15-58, en Acto de investidura como «doctores honoris causa»..., Alicante, Universidad, 1995.

22. Id.: «El interrogatorio de Albacete de Tomás López» (inédito).

23. Id.: «El interrogatorio y los mapas de Extremadura de Tomás López», Bol. Real Academia de la Historia, 1996 (en prensa).

24. Id.: «El interrogatorio y los mapas del Reino de Valencia de Tomás López», Cuadernos de Geografía (Valencia), 1996 (en prensa).

25. Id.: «Los domicilios en Madrid y el éxito de Tomás López» (inédito).

26. López Piñero, José, et al.: Diccionario histórico de la ciencia moderna en España, Barcelona, 1983 (sobre Tomás López, I, pp. 535-36).

27. Manso Porto, Carmen: Cartografía histórica de América. Catálogo de manuscritos (si glos XVIII-XIX), Madrid, Real Academia de la Historia, 1996 (en prensa). 
28. Marcel, Gabriel: Révue Hispanique, 1907, t. XVI, pp. 137-243; trad. esp. «El geógrafo Tomás López y sus obras. Ensayo de biografía y de cartografía», Bol. $R$. Academia de la Historia, 1908, LIII, pp. 126-243, y Bol. R. Soc. Geográfica, 1908, t. I, pp. 401-543.

29. Merinero, María Jesús, y Barrientos, Gonzalo: Asturias según los asturianos del último Setecientos, Oviedo, Principado de Asturias, Consejería de Educación, 1992, 297 p. 4 h.

29 bis. NúNEz de las Cuevas, Rodolfo: Historia de la Cartografía Española, Madrid, Real Academia de Ciencias Exactas, Físicas y Naturales, 1982.

30. Olarán Múgica, Clotilde: Indice de las relaciones geográficas enviadas a Tomás López que se conservan en el gabinte de Manuscritos de la Biblioteca Nacional, Madrid, 1987, ejemplar mecanografiado, en dicho gabinete.

31. Patier, Felicidad: La biblioteca de Tomás López, seguida de la relación de los mapas impresos, con sus cobres, y de los libros del caudal de venta que quedaron a su fallecimiento en Madrid en 1802, Madrid, Ediciones el Museo Universal, 1992, 271 pp.

32. Prudent, F.: «La cartographie de l'Espagne», Annales de Géographie, 1904, XIII, pp. 401-19.

33. Reguera Rodríguez, Antonio T.: «Cartografía y política. El proyecto de mapa de España desde su fundación (mediados del siglo xviII) hasta el comienzo de los trabajos (mediados del siglo xIx)», Estudios Geográficos, 1995, núm. 219, pp. 99-129.

34. R(EPARAZ) R(ePARAZ), G(onzalo) de: «Historia de la Geografía», pp. 9-134, en España. La tierra. El hombre. El arte, dir. J. Gavira, Barcelona, Alberto Martín, 1943, t. I, $588 \mathrm{pp}$.

35. Rodriguez de la Torre, Fernando, y CANo Valero, José: Relaciones geográfico-históricas de Albacete (1786-1789) de Tomás López, Albacete, Inst. Estudios Albacetenses, Dip. Albacete-CSIC, 1987, 364 pp.

36. Segura Graiño, C.: Tomás López. Diccionario geográfico de Andalucia: Sevilla, Granada, Ed. Don Quijote, 1989 (cortesía J. Bosque).

37. Vazquez Maure, Francisco: «Cartografía de la Península. Siglos XVI a XviII», pp. 5974, en Historia de la Cartografía Española, Madrid, Real Academia de Ciencias Exactas, Físicas y Naturales, Madrid, 1982. 